CITE AS: Málaga-Chuquitaype C, Elghazouli AY, 2010, Component-based mechanical models for blind-bolted angle connections, ENGINEERING STRUCTURES, Vol: 32, Pages: 3048-3067, ISSN: 0141-0296

\title{
Component-based mechanical models for blind-bolted angle connections
}

\author{
C. Málaga-Chuquitaype, A. Y. Elghazouli \\ Department of Civil and Environmental Engineering, Imperial College London, UK
}

\begin{abstract}
This paper deals with the prediction of the monotonic and cyclic response of blind-bolted angle connections between tubular columns and open beams. Firstly, the experimental study used for validation purposes is briefly described with focus on the required connection details and material properties. A mechanical model, based on the component approach, is then proposed and a detailed description of the model assumptions, component characterization, overall considerations and model validation is presented. The proposed mechanical model is also used to perform a parametric investigation into the key factors influencing the behaviour of blind-bolted angle connections. It is shown that the blind-bolt grade, angle thickness, column face slenderness and gauge distance have a significant influence on the connection behaviour. Based on these findings, simplified approaches for the estimation of the initial stiffness and moment capacity of blind-bolted connections are suggested. Failure mode considerations and simple expressions for ensuring the desired yield mechanism are also discussed. In addition to the detailed component model, this work provides information necessary for the development of practical design procedures for blind-bolted angle connections.
\end{abstract}

Keywords: 
Mechanical model, component model, angle connections, tubular columns, blind-bolts

$A_{b} \quad$ standard bolt cross sectional area

$a^{\prime} \quad$ effective distance between the point of application of $B_{b}$ and the root of the angle

$B_{b} \quad$ axial force in the standard bolt connecting the angle to the beam

$B_{c} \quad$ axial force in the Hollo-bolt connecting the angle to the column

$B_{y c} \quad$ column face yield strength

$b^{\prime} \quad$ effective distance between the points of application of $B_{b}$ and $Q_{b}$

$c_{f} \quad$ friction coefficient

$C_{t} \quad$ coefficient for the calculation of $k_{c f}$

$c^{\prime} \quad$ effective distance between the points of application of $B_{c}$ and $Q_{c}$

$d_{H b} \quad$ Hollo-bolt diameter

$D_{H} \quad$ Hollo-bolt hole diameter

$d^{\prime} \quad$ effective distance between the point of application of $B_{c}$ and the root of the angle

E Young's modulus

$F_{i} \quad$ bolt-row force

$f_{k} \quad$ factor for the calculation of $B_{y}$

$F_{p g} \quad$ axial force at the formation of plastic mechanism in the leg of the angle connected to the column (vertical leg)

$F_{p i} \quad$ bolt-row plastic axial force

$f_{p r y} \quad$ factor accounting for the change in the plastic hinge location in the leg of the angle component

$F_{\text {total }}$ total external axial force applied to the connection

$F_{y} \quad$ steel yield strength

$H \quad$ summation of beam height and bottom angle thickness

I moment of inertia of the angle cross section $\left(p t_{f}^{3} / 12\right)$

$L \quad$ horizontal spacing between Hollo-bolts in the bolt-row

$L_{b} \quad$ effective length of standard bolt mobilized in tension

$m_{b} \quad$ lever arm measured between the beam web and the point of application of $B_{b}$

$m_{p l a} \quad$ flexural plastic capacity of the angle leg

$m_{\text {plc }} \quad$ plastic moment of column face per unit length

$M_{\text {total }}$ total external moment applied to the connection

$m_{y} \quad$ flexural strength of the angle leg at yielding

$M_{y} \quad$ overall connection plastic moment capacity

$p \quad$ angle effective width

$P_{f} \quad$ friction slip resistance

$p_{p f} \quad$ pre-stressing force due to bolt tightening 
$k_{b f} \quad$ beam flange stiffness

$k_{c f} \quad$ column face tension stiffness

$k_{\text {comp }}$ column face compression stiffness

$k_{e q} \quad$ equivalent stiffness of web and top angle rows

$k_{g} \quad$ angle stiffness parameter used to relate $f_{\text {pry }}$ and $k_{H b}$

$k_{H b} \quad$ Hollo-bolt stiffness

$k_{i} \quad$ bolt-row stiffness

$k_{p i} \quad$ bolt-row strain hardening stiffness

$k_{s b} \quad$ standard bolt axial stiffness

$k_{\text {slip }} \quad$ stiffness related to bolt-slippage

$k_{t} \quad$ tensile stiffness of angle leg connected to the beam (horizontal leg)

$k_{T} \quad$ top angle bolt-row stiffness

$N \quad$ number of bolts in the bolt-row

$Q_{b} \quad$ prying force at the leg of the angle connected to the beam (horizontal leg)

$Q_{c} \quad$ prying force at the leg of the angle connected to the column (vertical leg)

$r \quad$ angle root radius

$t_{b} \quad$ beam flange thickness

$t_{f} \quad$ angle thickness

$t_{c} \quad$ column face thickness

$v \quad$ bolt-row displacement

$v_{p i} \quad$ bolt-row displacement at the attainment of the plastic capacity in the top angle

$y_{e q} \quad$ equivalent lever arm of web and top angle rows

$y_{i} \quad$ distance between bolt-row and reference datum

$y_{T} \quad$ distance between top angle bolt-row and the point of rotation of the joint

$\alpha, \alpha_{1}$ regression parameters for the calculation of the bolt-row capacity

$\gamma \quad$ factor used in the calculation of $B_{y}$

$\nu \quad$ Poisson's ratio

$\theta \quad$ overall joint rotation

$\theta_{p i} \quad$ overall joint rotation at the attainment of the plastic capacity in the top angle

\section{Introduction}

Column members made of Structural Hollow Sections (SHS) exhibit a number of advantages over their open section counterparts in terms of structural efficiency, robustness and aesthetic appeal. Nevertheless, the perceived difficulties associated with connecting open beams to tubular columns often result in an under-exploitation of these merits.

Previous investigations on open beam-to-tubular column connections have traditionally focused on fully-rigid/fully-welded connections [1, 2, 3, 4], and rules for the determination 
of the resistance of welded tubular joints have also been incorporated in current European standards [5]. On the other hand, it is recognised that semi-rigid bolted angle connections can offer economical and practical advantages in comparison with fully-rigid alternatives. Besides the avoidance of potential weld fracture problems associated with fully-rigid configurations, previous research $[6,7,8]$ has shown that properly designed bolted semi-rigid connections are often able to provide more favourable performance than fully-rigid details. This has lead to a considerable amount of research on this form of connections for open beam-to-open column joints [9, 10, 11, 12].

Following on from the above discussion, a number of investigations have been carried out in order to extend the economical and structural advantages of angle connections to frames incorporating tubular columns, for which several connection alternatives have been proposed. These alternatives include thermal drilling techniques like the flowdrill process $[13,14,15,16]$ and special bolts with sleeves designed to expand inside the clearance $[14,17,18,19,20]$. A simple and practical system is that proposed by Lindapter International [21] through the developement of the Hollo-bolt. Despite its wide availability and ease of practical use, experimental studies on connections incorporating Hollo-bolts had not, until recently, covered the full range of possible loading conditions [22, 23, 24, 25, 26, 27]. Based on monotonic tests on three end-plate joints, France [22] compared the behaviour of blind-bolts and flowdrilled bolts, and suggested that flowdrill systems can provide relatively higher stiffness and capacity. Barnett et al. [25, 26] performed a review of different blind-bolting options and carried out an experimental study on blind-bolted T-stubs and connections using Hollobolts. Wang et al. [24] carried out four tests on end-plate connections between open beams blind-bolted to concrete-filled tubular columns by means of Hollo-bolts, and good rotation capacity for the connections was reported. More recently, Elghazouli et al. [27] performed an experimental investigation into the monotonic and cyclic behaviour of blind-bolted top 
and seat and top, seat and web angle connections; in addition to offering insights into the key behavioural aspects of these connections, the results of this study also provide the basis for the development of the mechanical model presented in this paper.

Many studies have been carried out on the analytical modelling of semi-rigid connections incorporating conventional bolts. For example, Agerskov [28] and Yee and Melchers [29] contributed to some of the early studies on the well-established equivalent T-stub component model incorporated in Eurocode 3 [5]. Jaspart [30], Faella et al. [31], Swanson and Leon [32] and Lemonis and Gantes [33] proposed various multi-linear models which are able to produce good estimates of the complete force-displacement relationship for T-stub components. As for angle connections, Kishi and Chen [34] and Kishi et al. [35] developed parametric models for the prediction of moment-rotation curves of top and seat angle connections. De Stefano et al. [36] proposed a mechanical model for the prediction of the inelastic cyclic moment-rotation relationships of double-angle connections. Shen and Astaneh-Asl [37] developed a hysteretic model for top and seat angle specimens which distinguishes between the behaviour of "thin" and "thick" angles. Garlock et al. [9] also performed experimental and analytical studies on bolted angle components with emphasis on their hysteretic behaviour.

In contrast, analytical research on the response prediction of blind-bolted connections to tubular columns is scarce. Ghobarah et al. [38] suggested an analytical model for the evaluation of the initial stiffness and plastic moment capacity of blind-bolted end-plate connections between open beams and tubular columns. Silva et al. [39] presented an analytical model for the estimation of the column face stiffness in end-plate connections with concrete filled tubular column components; representative expressions were proposed based on finite element models as well as experimental results. However, available models on end-plate connections cannot be directly applied to blind-bolted connections with angles due to the 
significant influence of contact phenomena as well as the complex interactions between the blind-bolts, column face and angle components as observed clearly in recent experimental studies [27]. Accordingly, there is a need for a dedicated model that provides a faithful characterisation of the response of blind-bolted angle connections. Such model should also be capable of predicting the response under cyclic loading conditions.

The dearth of research studies on semi-rigid bolted angle connections for tubes is also reflected in the limited design guidance available [40, 41]. Yeomans [40] proposed some criteria for the failure of bolts and column face, whilst CIDCET Design Guide 9 [41] suggests that simple shear connections can be designed with available guidance for open columns although special attention needs to be given to the column face deformation. On the other hand, AISC [42] suggests minimum thickness according to the bolt type for angle connections. In contrast, there is no consideration of blind-bolted connections to tubular columns in the current European standards [5].

This paper presents a mechanical model for the prediction of the response of blind-bolted angle connections between open beams and tubular columns. The proposed model is based on the component approach in conjunction with incremental procedures, and is able to trace the full monotonic and cyclic moment-rotation response of angle connections incorporating Hollo-bolts. After validation against experimental results, the model is employed in a parametric investigation into several key factors influencing the behaviour of blind-bolted angle connections, namely: the blind-bolt grade, angle thickness, column face slenderness and gauge distance (defined here as the vertical distance between the centreline of the blind-bolt and the base of the angle connected to the column). Based on the findings of the parametric assessment, simplified semi-analytical expressions are proposed for the estimation of the initial stiffness and moment capacity. Finally, several considerations related to failure mode 
control and rotation ductility are highlighted.

\section{Experimental programme}

This section gives a brief summary of the experimental study carried out by Elghazouli et al. [27] and used herein for validation purposes. The study comprised seventeen tests performed on blind-bolted top and seat as well as top, seat and web angle connections between open beams and tubular columns, and included both monotonic and cyclic loading conditions.

Table 1 presents a summary of the tests performed including the geometric details of the connection as well as the beam and column sizes. Column sections are referred to as RHS or SHS (i.e. Rectangular Hollow Section or Square Hollow Section), while UB stands for Universal Beam. It is important to note that whenever RHS were used as columns, the beam was connected to the wider face. Figure 1 illustrates the three connection configurations utilised (A, B and C) and referred to in Table 1. The nomenclature used for the specimens follows the format $T t-G x-d y-R$ where $T$ represents the specimen type (A, B or C in Figure 1$), t$ the column face thickness in mm, $G$ is short for grade, $x$ represents the Hollo-bolt grade, $d$ is short for distance,$y$ represents the gauge distance between the centre of the Hollo-bolt and the beam flange in $\mathrm{mm}$, and $R$ reflects the testing regime ( $\mathrm{M}$ for monotonic and $\mathrm{Y}$ for cyclic).

Grade 8.8 M16 standard bolts were employed for connecting the angles to the beam whereas the grade of the Hollo-bolt connecting the angle to the tubular column was either 8.8 or 10.9 depending on the test. The grade of steel used for the beam and angle members was S275, while S355 was utilized for the columns. The average yield strength values obtained from coupon tests for the beam, angle and column specimens were 329, 312 and $400 \mathrm{~N} / \mathrm{mm}^{2}$ respectively, while average values of 443, 438 and $502 \mathrm{~N} / \mathrm{mm}^{2}$ were obtained for the ultimate 
strength of the beam, angle and column specimens, respectively.

The experimental study [27] included ten monotonic and seven cyclic beam-to-column connection tests conducted under displacement-control conditions. For the cyclic tests, maximum rotations of up to $\pm 66 \mathrm{mrad}$ were accommodated in both directions and the testing protocol shown in Figure 2 was used based on the recommendations provided by ECCS [43] where $\theta_{y}$ refers to the rotation at yield. More detailed information on the experimental study can be found elsewhere [27].

Overall, the experimental study illustrated that blind-bolted connections as those examined in this paper, possess significant ductility and hardening characteristics under monotonic and cyclic loading. In terms of ductility, connections with or without web angles provided rotational capacity in excess of 120 mrad under monotonic loading and more than $60 \mathrm{mrad}$ under cyclic loading, which are well beyond those required under typical design conditions. The connections also exhibit stable hysteretic response and provide reasonable energy dissipation capabilities, despite the notable pinching behaviour in some cases. In general, blind-bolted beam-to-column connections of the type examined in this paper are mostly suitable for braced frames, or as moment connections in secondary lateral resisting systems (which are typically assumed to carry less than 10\%-20\% of the base shear). Their use as moment connections in lateral resisting systems of unbraced/moment frames is likely to be restricted to relatively low-rise construction subjected to comparatively modest levels of seismic or wind loads. 


\section{Model development}

\subsection{General}

The response of angle connections generally involves various complex interactions between the constituent components. Additionally, recent experimental assessments [27] have demonstrated that blind-bolted angle connections exhibit specific behavioural characteristics that further complicate the response. Overall, the modelling approach should consider, among others: (i) the relatively high axial (and flexural) flexibility of the blind-bolts, (ii) influence of plasticity in the horizontal (beam side) angle leg, (iii) angle membrane effects at large displacements, and (iv) significant strain hardening effects. The mechanical component-based model described in this paper incorporates these effects and enables a faithful simulation of the response of open beam-to-tubular column connections with angles under monotonic and cyclic loading conditions. A multi-linear incremental approach which, in various different forms, has been applied to T-stub components [32, 33, 44], is utilised here in order to trace the non-linear inelastic force-deformation response of the angle component. Furthermore, the flexibility of each component is considered separately and the interaction between them is accounted for through the underlying mechanics with due consideration of the evolution of prying forces.

In general, any typical connection configuration (such as the one presented in Figure 3a) can be idealised as an assemblage of uniaxial springs as shown in Figure 3b . Each spring in Figure $3 \mathrm{~b}$ represents the contribution of an individual bolt-row. Figure $3 \mathrm{c}$ shows the notation and dimensions used at the bolt-row level. The stiffness of each bolt-row $k_{i}$, is intrinsicly non-linear and can be estimated by means of the mechanical model depicted in Figure 3d. In this figure, $k_{c f}$ is the stiffness of the column face acting in series with the Hollo-bolt axial stiffness $\left(k_{H b}\right), k_{b f}$ is the beam flange stiffness, $k_{s b}$ is the axial stiffness of the standard bolt connecting the angle to the beam, $k_{t}$ is the tensile stiffness of the horizontal leg of the angle, 
and $k_{\text {slip }}$ represents a rigid-plastic element that takes into account the deformations due to bolt-slippage.

It should be noted that although Figure 3c appears to represent a top angle, the same model characteristics described above are used for bolt-rows involving web angle components, provided the appropriate width is used in the model, and $k_{b f}$ is considered as infinite to account for the symmetry in applied forces typical of web angle components. Finally, in order to satisfy equilibrium between internal forces and external actions (moment $M_{\text {Total }}$ and force $F_{\text {Total }}$ in Figure $3 \mathrm{~b}$ ), each bolt-row resists a horizontal force $F_{i}$ (either in tension or compression) and hence:

$$
\begin{gathered}
F_{\text {Total }}=\sum F_{i} \\
M_{\text {Total }}=\sum F_{i} y_{i}
\end{gathered}
$$

where $y_{i}$ defines the location of the bolt-row with respect to any reference datum. The following sub-sections describe the characterisation employed for each component and the means by which individual component responses are assembled.

\subsection{Prying action}

The prying forces, $Q_{c}$ at the vertical (column) leg and $Q_{b}$ at the horizontal (beam) leg of the angle, are idealised as point loads located at a distance $c^{\prime}$ or $b^{\prime}$, respectively, from the bolts, as indicated in Figure 3c. The yielding zone near the root of the angle is assumed to be located at a distance of $0.8 r$ from the face of the angle, with $r$ being the root radius.

The axial forces $B_{c}$ and $B_{b}$ are transmitted to the bolts connecting the angle to the column and the beam, respectively. Force $B_{b}$ is assumed to develop at the inside edge of the bolt 
connecting the angle to the beam based on the prying model suggested by Struik and de Black [45]. The force $B_{c}$, is assumed to be located between the bolt centreline and the edge of the bolt connecting the angle to the column in order to account for the inherent rotational flexibility of the Hollo-bolt. For more flexible angle legs, plastic hinges were observed at the inside edge of the bolt during the tests [27]. On the other hand, when relatively stiff angles were used, plastic hinges tended to move closer to the Hollo-bolt centreline. Accordingly, the distances $c^{\prime}$ and $d^{\prime}$ are defined as follows:

$$
\begin{gathered}
c^{\prime}=c+\left(1-f_{\text {pry }}\right) \frac{d_{H b}}{2} \leq 1.25\left(d-0.8 r-t_{f}\right) \\
d^{\prime}=d-\left(0.8 r+t_{f}\right)-\left(1-f_{\text {pry }}\right) \frac{d_{H b}}{2}
\end{gathered}
$$

where dimensions $c$ and $d$ are measured as specified in Figure $1, t_{f}$ is the angle thickness, $r$ the angle root radius, $d_{H b}$ the Hollo-bolt diameter and $f_{\text {pry }}$ a factor that takes into account the change in the location of the plastic hinge. Figure 4 presents the assumed variation in the factor $f_{\text {pry }}$ as a function of the ratio between the stiffness of the blind-bolt (defined as $\left.k_{H b}\right)$ and the value of $k_{g}$, which is a parameter that reflects the relative stiffness of the angle leg with respect to that of the Hollo-bolt, and is defined here as:

$$
k_{g}=\frac{E I}{\left(d-t_{f}-0.8 r\right)^{3}}
$$

It is evident from Figure 4 that for stiffer angle configurations, the plastic hinge will be displaced towards the centreline of the Hollo-bolt (i.e. $f_{p r y}=1$ ), whereas for more flexible configurations the plastic hinge zone would be located at the inside edge of the Hollo-bolt towards the root of the angle (i.e. $f_{\text {pry }}=0$ ). A linear interpolation between the limit values of $k_{H b} / k_{g}=3$ and $k_{H b} / k_{g}=12$ was found to provide close agreement with experimental results and observations. A value of around $200 \mathrm{kN} / \mathrm{mm}$ corresponding to the initial stiffness 
of the Hollo-bolt was used for $k_{H b}$ during the calculation of $c^{\prime}$ and $d^{\prime}$, in accordance with typical experimental values reported elsewhere [27] and summarized in Figure 5 and Table 2. Furthermore, once initially set, the distances $c^{\prime}$ and $d^{\prime}$ are assumed to remain constant throughout the stiffness calculation process.

\subsection{Column face component}

A bi-linear idealisation of the force-displacement response of the column face component is used. The initial stiffness is obtained by an adaptation of the stiffness model available for open columns [46] as:

$$
k_{c f}=\frac{\pi E t_{c}{ }^{3}}{12\left(1-\nu^{2}\right) C_{t}\left(\frac{b_{c}-t_{c}}{2}\right)^{2}}
$$

where $E$ is the elastic modulus of steel, $t_{c}$ is the column face thickness, $\nu$ is the Poisson's ratio for steel, $b_{c}$ the column face width and $C_{t}$ is a coefficient assumed as 0.18 based on the results of detailed continuum numerical studies [46].

The tension force $\left(B_{y c}\right)$ that would cause yielding of the column face is calculated based on an adaptation of the expressions developed by Gomez [47], and is considered as the minimum of the punching resistance $\left(B_{y 1}\right)$ and local yielding capacity $\left(B_{y 2}\right)$, thus:

$$
B_{y c}=\min \left(B_{y 1}, B_{y 2}\right)
$$

where $B_{y 1}$ is calculated from the following equation:

$$
B_{y 1}=\left(\begin{array}{ccc}
\frac{N \pi D_{H} t_{c} F_{y}}{\sqrt{3}} & \text { if } & 2\left(L+0.9 D_{H}\right) \geq N \pi D_{H} \\
\frac{2\left(L+0.9 D_{H}\right) t_{c} F_{y}}{\sqrt{3}} & \text { if } & 2\left(L+0.9 D_{H}\right)<N \pi D_{H}
\end{array}\right.
$$

and $B_{y 2}$ is determined from: 


$$
B_{y 2}=f_{k} \gamma m_{p l c}
$$

where $m_{p l c}$ is the plastic moment of the column face by unit length, $D_{H}$ is the bolt hole diameter, $N$ the number of bolts, $F_{y}$ the yield stress, $L$ is the spacing between two Hollobolts in the same bolt-row (e.g. $i$ in Figure 1), and factors $f_{k}$ and $\alpha$ are calculated from Equations 10 and 11 as follows:

$$
\begin{gathered}
f_{k}=\left(\begin{array}{lrl}
1 & \text { if } & \frac{L+0.9 D_{H}}{b_{c}} \geq 0.5 \\
0.7+\frac{0.6\left(L+0.9 D_{H}\right)}{b_{c}} & \text { if } & \frac{L+0.9 D_{H}}{b_{c}}<0.5 \\
\gamma=\frac{4}{1-L / b_{c}}\left(\pi \sqrt{1-\frac{L}{b_{c}}}\right)+1.8 \frac{D_{H}}{b_{c}}
\end{array}\right.
\end{gathered}
$$

Finally, the post yield stiffness is assumed to be $10 \%$ of the initial stiffness in line with typical values found by other researchers [38].

\subsection{Hollo-bolt response}

A multi-linear idealization of the axial force-displacement relationship is used to model the Hollo-bolt response. Figure 5 presents the comparison between typical experimental results [27] and the proposed idealization for M16 Hollo-bolts of Grade 10.9 and 8.8. The corresponding force-displacement values are given in Table 2.

\subsection{Beam flange stiffness}

The beam flange connected to the top or seat angle is assumed to remain elastic, and its stiffness is evaluated as follows:

$$
k_{b f}=\frac{2 E \pi t_{\text {beam }}^{3}}{m_{b}^{2}} N
$$


where $t_{\text {beam }}$ is the flange thickness and $m_{b}$ is the lever arm to the point of application of load $B_{b}$ measured from the face of the beam web, as depicted in Figure 1a. Importantly, as mentioned before, when web angle components are being evaluated, the value of $k_{b f}$ can be assumed as infinite. This is a reasonable assumption, given negligible net forces that act in the out of plane direction for the web of the beam due to symmetrically applied forces.

\subsection{Standard bolts}

The elastic stiffness of the standard bolts that connect the angle to the beam is calculated as:

$$
k_{s b}=\frac{A_{b} E}{L_{b}} N
$$

were $N$ is the number of bolts considered to contribute to the stiffness of the bolt-row, $A_{b}$ is the cross sectional area of a single bolt and $L_{b}$ the effective length of a single bolt subjected to axial tension. This effective length corresponds to the bolt segment subjected to tension and is typically measured between the head and the shank of the tightened bolt [5].

\subsection{Tensile behaviour of horizontal leg (beam side)}

Axial tensile deformation is considered only in the horizontal leg of the angle connected to the beam, whereas any tensile deformation in the vertical leg (column side) of the angle is ignored. This was considered adequate in light of the relatively limited contribution of the axial flexibility of the angle legs, a contribution that is further reduced in the case of the vertical leg due to the orthogonality of the applied load, particularly at early stages. The axial tensile stiffness of the horizontal leg of the angle is determined from:

$$
k_{t}=\frac{E p t_{f}}{a^{\prime}}
$$


where $p$ is the angle width ( $h$ in Figure 1 ) for top and seat angles or an effective width in the case of web angle components.

\subsection{Bolt slippage}

A rigid-plastic force-displacement relationship is considered for the slippage in the standard bolts. No deformation is assumed up until the applied force overcomes the friction slip resistance $P_{f}$. Such friction resistance can be calculated as the product of the friction coefficient $c_{f}$ and the pre-stressing force $p_{p f}$ applied during the tightening process, hence:

$$
P_{f}=c_{f} p_{p f} N
$$

Once $P_{f}$ is reached, a slip displacement up to the bolt hole tolerance occurs in the bolt-row component. A friction coefficient of 0.2 is assumed as a default value in the present model, and a value of $40 \mathrm{kN}$ was assumed for $p_{p f}$ in accordance with tests.

\subsection{Force-displacement solution procedure}

The model presented above, is solved using an incremental procedure within which the stiffness $k_{i}$ can take values corresponding to any of the possible states depicted in Figures 6 and 7. In this study, the solution process is divided in two phases. Figure 6 presents the scheme of possible behavioural stages for the first phase (Phase I) in which all deformations are assumed to concentrate in the vertical (column side) leg of the angle component. As depicted in Figure 6, eleven deformational stages are possible, including two corresponding to complete angle-column separation modes that may occur in blind-bolted connections given the inherent flexibility of the Hollo-bolts. Such angle-column separation occurs when the prying force $Q_{c}$ (see Figure 3d) becomes zero and the vertical leg of the angle acts as a cantilever beam; nevertheless, stresses will start to concentrate near the root radius, hence a plastic hinge will eventually develop and the contact between the angle tip and the column 
face will be re-established.

The effects of material hardening that were observed to have a significant influence on the behaviour of angle connections $[27,37,48]$ are accounted for in the model by: (i) introducing rotational springs at the locations where the angle section becomes fully plastic and (ii) assuming a variable strain hardening modulus $\left(E_{s h}\right)$. To this end, it was observed that, some plastic regions experience relatively high strain levels which, depending on the type of material, can result in significant hardening effects. Accordingly, a varying strain hardening modulus was used in the calculations. For States $k_{I e p}$ and $k_{I p e}$ in Figure 6 , the strain hardening modulus is set to $0.5 \%$ of the steel elastic modulus (i.e. $E_{s h}=0.005 E$ ), whereas for states $k_{I y p}, k_{I p y}$ and $k_{I p p}$ the strain hardening modulus can change to a higher value (assumed as 1.5\%). Appendix A presents the expressions used to calculate the stiffnesses at each stage of Phase I.

The solution algorithm outlined by Swanson and Leon [32] for T-stub components was adapted here for angle components and implemented in MATLAB [49]. The process starts with the calculation of moment limits by considering: (i) the flexural plastic capacity of the angle leg, given as:

$$
m_{p l a}=\frac{F_{y} p t_{f}^{2}}{4}
$$

and (ii) the moment $\left(m_{y a}\right)$ at the instant in which the yield stress is attained in the outer fibres of the angle section, represented by:

$$
m_{y a}=\frac{F_{y} p t_{f}^{2}}{6}
$$

Subsequently, limiting values for the increments in force $\Delta F_{i}$ are evaluated as those that 
would cause: (i) yielding or (ii) full plasticity at the critical sections, (iii) change of stiffness values in the multi-linear relationship of the Hollo-bolt as given in Table 2, or (iv) reduction of the prying force $Q_{c}$ of Figure $3 \mathrm{~d}$ to zero. The actual force increment $\Delta F_{i}$ is considered as the lowest of these four possible values, hence governing which branch of the decision tree of Figure 6 is subsequently followed.

The second deformation phase (Phase II), shown in Figure 7, starts with the angle vertical leg acting as a mechanism, with rotational stiffness provided by the strain hardening at the plastified critical sections. Prying forces are considered in the same manner as before but no plasticity is expected at the standard bolt location in the beam-side (horizontal) leg of the angle. During Phase II, similar expressions as those presented in Appendix A for the calculation of horizontal displacements in the vertical (column side) leg of the angle, are used to calculate vertical displacements in the horizontal (beam side) leg of the angle. Subsequently, by assuming axial in-extensibility in the vertical leg, these vertical displacements of the horizontal leg are transformed into additional force-displacement pairs at the bolt-row level through pure geometrical considerations. In this way, geometric non-linearity is directly accounted for and hence the experimentally-observed stiffening effects at large displacements are reasonably incorporated. It is important to note that the deformation patterns of Phase II were experimentally observed only when the stiffness of the combined column and Hollobolt provided sufficient deformational restraint. Hence, the model assumes that Phase II modes become inactive whenever significant lateral deformations start to accumulate in the column-side (vertical) leg of the angle. Such limiting condition is reached if yielding in the column face occurs in the model (as evaluated from Equation 7). The solution process is continued until the ultimate capacity of the Hollo-bolt is reached. The same overall solution process is followed for bolt-rows located either in the top or web angle regions, with due consideration of the appropriate effective width. 


\subsection{Hysteretic rules and overall joint response}

Figure 8 depicts the hysteretic model assumed in the present study for a bolt-row. A non-linear characterisation of the horizontal force-displacement relationship for a single boltrow is possible by means of the incremental mechanical model described previously. Hence, the loading stiffness (denoted $k_{i}$ in Figure 8) can be evaluated. The unloading branch of the curve presented in Figure 8 can be obtained by assuming a force-displacement relationship equal to two times the initial loading branch in accordance with conventional practice [9, 37]. Once zero displacement is reached (i.e. contact between the column face and the angle is fully re-established), additional compression forces will push the column face inwards with a column face compression stiffness $k_{\text {comp }}$ taken as that previously proposed for tension effects in Equation 6 for simplicity. Additional re-loading stages (denoted $k_{\text {reloading }}$ in Figure 8) are always assumed to start from the origin and to develop linearly towards the maximum displacement reached previously in order to account, in a simple manner, for the stiffness degradation effects observed during the tests.

In the case of cyclic loading, the hysteretic rules described above are applied for each boltrow component forming the multi-spring joint model considered in Figure 3b. Under either monotonic or cyclic loading, compatibility and equilibrium conditions are then imposed in order to obtain the full moment-rotation response at the overall joint level. This solution process involves the evaluation of the equilibrium of forces at a number of rotation increments $\Delta \theta$. Equilibrating moment-rotation points are identified by binary interpolation and successively stored until the specified final rotation is reached. 


\section{Comparison with test results}

The mechanical model proposed in the previous section was validated against the results of the experimental programme described in Section 2 [27]. Figure 9 presents the comparisons between the moment-rotation curves predicted by the mechanical model and the experimental results for top and seat angle connections under monotonic loading, whilst Figure 10 presents the same comparisons for top, seat and web angle connections. It should be noted that the bolt slippage component was insignificant and can therefore be ignored when simulating the response of top and seat angle connections under monotonic loading as the slip onset forces were reached at relatively large rotations in the tests. On the other hand, slip behaviour can occur comparatively early in the case of top, seat and web angle connections and hence needs to be adequately represented in the model by incorporating the actual clearance (typically 1 - $2 \mathrm{~mm}$ ). This was particularly evident for Specimen B10G8.8-d40-M (see Figure 10a) where the difference between the experimental and analytical responses can be attributed to the gradual slippage occurring between rotations levels of 5 and $18 \mathrm{mrad}$. In contrast, slippage is considered to occur instantaneously in the mechanical model once the assumed friction resistance is reached.

As demonstrated in Figures 9 and 10, the mechanical model predictions are in close agreement with the experimental results. The model is able to represent the key response parameters and features of the blind-bolted connections, namely the initial stiffness, connection capacity, post-yield hardening and onset of membrane effects at large displacements. The initial stiffness and capacity are predicted within an accuracy of under $5 \%$ in all cases. Some observed discrepancy in the response at large rotation levels (more than $40 \mathrm{mrad}$ ) can be attributed to modelling idealization of the material hardening. Worthy of note, Specimen A10-G10.9-d40-M in Figure 9g reached the Hollo-bolt ultimate deformation capacity at a moment of $43 \mathrm{kNm}$ both in the test [27] and in the mechanical model prediction. 
Figures 11 and 12 depict the comparative hysteretic curves for top and seat angle connections and top, seat and web angle connections, respectively. Only the response between the fifth and ninth cycle of Figure 2 is presented for clarity. It is evident form Figures 11 and 12 that the mechanical model provides a reasonably good prediction of the hysteretic response including strength degradation effects. The degradation in stiffness during the initial stages of the unloading/reloading phases is, nevertheless, slightly under-predicted (notably for Specimen A6.3-G8.8-d40-C in Figure 11c). This is attributed to the idealisations considered in the adopted hysteretic rule for the bolt-row (see Figure 8). In general, however, the mechanical model captures the main features of the cyclic response.

\section{Parametric assessments}

Having gained confidence in the reliability of the detailed component model, a number of parametric and sensitivity studies were carried out in order to investigate the influence of key factors on the stiffness, capacity and ductility of blind-bolted connections. To this end, and in order to facilitate the interpretation of results, the response of a single boltrow is examined herein. The selected bolt-row consists of a top angle blind-bolted to a tubular RHS column by means of two Hollo-bolts and attached to the beam through two M16 standard bolts. The distance between the centrelines of the Hollo-bolts (i.e. dimension $i$ with reference to Figure 1) is set to $45 \mathrm{~mm}$ and Grade S275 steel is used. All other geometric parameters and material properties are varied within expected practical ranges. Specific assessments, which offer additional insights into the behaviour or provide useful information for calibrating more simplified models, are selected and discussed below. This is carried out with reference to Figures 13 to 18 in which the bolt-row force $\left(F_{i}\right)$ against the bolt-row displacement $(v)$, as well as the separation of the Hollo-bolt relative to the column face, are presented. 


\subsection{Angle thickness and Hollo-bolt grade}

The influence of the angle thickness is examined in Figures 13 and 14 which present the results for blind-bolted connections between a 150x18 SHS column and a 100x75 angle with varying thickness. Other geometric dimensions of Figure 1 are set as $a=45 \mathrm{~mm}, \mathrm{~b}=30$ $\mathrm{mm}, \mathrm{c}=35 \mathrm{~mm}, \mathrm{~d}=65 \mathrm{~mm}$ and $\mathrm{h}=100 \mathrm{~mm}$, and M16 Hollo-bolts of Grade 10.9 or 8.8 are used. It is worth noting that whenever the Hollo-bolt deformation capacity is reached, the corresponding force-displacement curve is terminated. This occurs at blind-bolt deformations equal to $4.5 \mathrm{~mm}$ for Grade 10.9 Hollo-bolts and 7.6 for Grade 8.8. As expected, the angle thickness has a significant and direct effect on the bolt-row capacity which increases proportionally with its increase.

Largely similar force-deformation responses are obtained irrespective of the Hollo-bolt grade, and the direct relationship between angle thickness and yield strength is maintained by com-

paring Figures 13a and 14a. The main difference, however, is that of the reserve capacity as can be more easily observed in Figures 13b and 14b. Grade 10.9 bolts yield at bolt-row displacements of about 11-13 $\mathrm{mm}$ and attain fracture conditions only at large angle displacements (over $25 \mathrm{~mm}$ ). Grade 8.8 Hollo-bolts, on the other hand, start accumulating displacements well before and reach ultimate deformation capacity (assumed as approximately $7.5 \mathrm{~mm}$ ) at angle displacements as low as $12 \mathrm{~mm}$.

In addition to the above, when Grade 10.9 Hollo-bolts are employed, the bolt-row displacement associated with yielding in the blind-bolt (between 11 and $13 \mathrm{~mm}$ ) is only slightly affected by the change in angle thickness as shown in Figure 13b. This is due to the improved stiffness characteristics of Grade 10.9 Hollo-bolts caused by the allowance of higher tightening torque. In contrast, when Grade 8.8 Hollo-bolts are used, the relationship between global bolt-row displacement and blind-bolt yielding is more involved (as can be appreciated 
from Figure 14b). This has direct implications on the reliability of possible expressions for ductility assessment and verifications of serviceability displacement limits in the Hollo-bolts.

\subsection{Column face flexibility and Hollo-bolt grade}

The column face flexibility is characterised here by means of its slenderness, defined as the ratio between the width $b_{c}$ and thickness $t_{c}$ of the face of the structural hollow section under consideration. The bolt-row analysed is formed by a 100x75x8 mm angle connected with the shorter leg to the column, hence the dimensions of Figure 1 are maintained as $\mathrm{a}=$ $50 \mathrm{~mm}, \mathrm{~b}=50 \mathrm{~mm}, \mathrm{c}=35 \mathrm{~mm}, \mathrm{~d}=40 \mathrm{~mm}$. The column section is varied betwen SHS of dimensions 150x18, 200x16, 150x10, 200x10, 300x10, 200x5 and 300x6.3, resulting in ratios of $b_{c} / t_{c}$ of $8,13,15,20,3040$ and 48 , respectively. Figure 15 depicts the bolt-row force versus bolt-row displacement as well as the blind-bolt separation versus bolt-row displacement for Grade 10.9 Hollo-bolts. Figure 16 shows the corresponding results for Grade 8.8 Hollo-bolts.

The direct influence of the column face flexibility on both the connection stiffness and capacity is evident from Figures 15 and 16. Stiffer column faces will cause inelasticity to be developed either in the angle or ultimately in the blind-bolts, whereas relatively flexible column faces will yield first subsequently reducing the strength demands imposed on other connection components, but at the expense of lower connection capacities. It is important to note, however, that significant column face yielding is associated with high strain hardening and ductility capacities and can form a desirable failure mode when initial stiffness considerations are not the primary concern. In this respect, the use of Grade 10.9 Hollo-bolts offers a favourable behaviour as the onset of column face yielding can be more clearly defined. This is corroborated by comparing Figures $15 \mathrm{~b}$ and $16 \mathrm{~b}$, where yielding of the column face occurs for $b_{c} / t_{c}$ values of 20 or greater for Grade 10.9 Hollo-bolts. In contrast, the comparatively early yielding for Grade 8.8 Hollo-bolts initiates intricate component interactions 
that can render the definition of such behavioural boundaries more complex and less reliable.

\subsection{Gauge distance and Hollo-bolt grade}

In order to assess the influence of the gauge distance, a set of connections between a 150x10 SHS column and various angle sections is considered herein. The angle sections utilised are $75 \times 100 \times 10,100 \times 75 \times 10,125 \times 75 \times 10,150 \times 75 \times 10$ and 200x100x10 mm, hence the distance $d$ (see Figure 1) varies between 40, 65, 85, 115, and $165 \mathrm{~mm}$, respectively. The load-deformation curves at the bolt-row level are shown in Figures 17a and 18a, whilst the curves for the blind-bolt separation versus the bolt-row deformation are depicted in Figures $17 \mathrm{~b}$ and $18 \mathrm{~b}$.

As shown in Figures 17a and 18a, as the gauge distance $d$ increases, the stiffness (and capacity) of the angle connection decreases irrespective of the grade of the blind-bolt used. More flexible angle components also cause the blind-bolt yield forces to be achieved at proportionally larger displacements. This direct relationship between the gauge distance and overall displacement at the yield of the blind-bolt is maintained as indicated in Figures $17 \mathrm{~b}$ and $18 \mathrm{~b}$ (with the yielding occurring relatively earlier in Grade 8.8 bolts as expected).

\section{Design considerations}

The detailed component model described in this paper can be used for assessing accurately the behaviour of connections in non-linear analytical simulations of framed structures or for conducting further parametric examinations. However, for practical design purposes, there is a need for more simplified procedures. Accordingly, the observations and findings discussed in previous sections are used herein to propose simplified expressions that are suitable for practical design, and to highlight various design implications of blind-bolted angle 
connections. Particular focus is given to the evaluation of the initial stiffness, yield capacity, post-elastic stiffness and failure mode. For this purpose, the mechanical model described previously in this paper, was used to generate additional data on key parameters. This information was subsequently used to propose simplified expressions for the force-displacement response at the bolt-row level as described in the following sections.

\subsection{Initial stiffness}

For determining the initial stiffness, a direct application of the initial stage of the mechanical model described previously is proposed. This initial stiffness corresponds to $k_{I e e}$ in Figure 6 and can be simplified as:

$$
k_{\text {Iee }}=k_{i}=\frac{12 E I\left(3 E I d^{\prime 3}+\left(\frac{1}{1 / k_{c f}+1 / k_{H b}}\right) c^{\prime 2}\left(1+3 d^{\prime}\right)\right)}{12 E I\left(c^{\prime}+d^{\prime}\right)^{3}+\left(\frac{1}{1 / k_{c f}+1 / k_{H b}}\right) c^{\prime 2}\left(4 c^{\prime}+3 d^{\prime}\right)}\left(1-\frac{d^{\prime}}{3\left(d^{\prime}+a\right.}\right)
$$

where $I$ is the moment of inertia of the longitudinal section of the angle (i.e $\left.p t_{f}^{3} / 12\right), c^{\prime}$ and $d^{\prime}$ are the distances defined by Equations 3 and $5, a$ is the gauge distance of the horizontal leg of the angle measured as indicated in Figure $1, k_{c f}$ is the column face stiffness which can be evaluated from Equation 6 , while $k_{H b}$ represents the Hollo-bolt initial stiffness which can be obtained from the force-displacement values reported in Table 2.

In order to ensure conservative estimates, Equation 18 includes a factor that considers the influence of the horizontal leg flexibility on the overall initial stiffness. It is also important to note that stiffness values may depart from linearity at early loading stages when large forces are coupled with significant column face deformations (which may be particularly important 
in the compression zones of web angle connections as is the case of Specimen B10-G10.9d40-M). In such cases, and as pointed out in the experimental study [27], this undesirable behaviour can be designed-out by either employing wider beam flanges or adding plates so as to ensure adequate load distribution to the stiffer parts of the tubular column.

\subsection{Failure mode}

A reliable prediction of the plastic mechanism in blind-bolted angle connections is essential in order to ensure a predictable structural performance. In particular, the implications of the dominant mechanism on the capacity and ductility of the blind-bolted connection should be appropriately considered. In this context, a clear definition of the necessary conditions for the attainment of a specific plastic mode can ensure the elimination of undesirable failure mechanisms. Based on the analytical results and experimental observations obtained within the present study, the following considerations with regards to failure mode control can be identified:

- The use of Grade 10.9 Hollo-bolts is useful in delaying the onset of yielding in the blind-bolt, while at the same time ensuring a more reliable definition of the angle deformation patterns. This, considered alongside the fact that the bolt-separation at the initial deformation stages (Stages $k_{S e e}$ and $k_{S e y}$ in Figure 6) was mostly observed when Grade 8.8 bolts were used, makes it desirable to use Grade 10.9 Hollo-bolts instead of the conventional Grade 8.8.

- As expected, the column face flexibility has a direct influence on the stiffness and capacity of blind-bolted angle connections. In general, two main related failure states are possible: (i) concentration of deformation in the column face, for more flexible column faces, and (ii) deformation mainly concentrated in other joint components with subsequent failure of the Hollo-bolt at large deformation demands for stiffer column faces. The column face slenderness values $\left(b_{c} / t_{c}\right)$ for which concentration 
of the deformation in the column face is expected are found to be greater or equal to 20 for Grade 10.9 Hollo-bolts. Also, Equation 7 could be compared with the yield strengths reported for Hollo-bolts (e.g. Table 2) in order to asses the likelihood of column face yielding around the Hollo-bolt insert.

- Provided Grade 10.9 Hollo-bolts are employed, relationships of the form depicted in Figure 19 can be used to estimate the bolt-row displacement at which yielding of the blind-bolt occurs. This may result in undesirable separations between the blind-bolt nut and the column face, which is likely to violate serviceability requirements. As illustrated in Figure 19, such bolt-row displacement limit is found to be a function of the ratio $h t_{f} / d^{\prime 2}$ where $h$ is the angle width (from figure 1 ), $t_{f}$ the angle thickness and $d^{\prime}$ the gauge distance as defined before.

\subsection{Bolt-row capacity}

The plastic axial force $\left(F_{p i}\right)$ at the bolt-row is largely a function of the plastic moment capacity of the angle leg $\left(m_{p l a}\right)$, as defined by Equation 16, and the gauge distance $d^{\prime}$. As discussed before, the number and location of plastic hinges result from complex interactions between the blind-bolt, angle and column components. However, provided that (as discussed in Section 6.2): (i) the deformation in the Hollo-bolts is limited, and (ii) the capacity is not mainly governed by column face yielding, then a general simplified equation of the following form could be sought:

$$
F_{p i}=\alpha F_{p g}=\alpha \frac{2 m_{p l a}}{d^{\prime}}
$$

Figure 20 presents the values of $\alpha$ as a function of column slenderness $b_{c} / t_{c}$ for different values of $d^{\prime} / t_{f}$. Using linear curve fitting and linear interpolation, the general equation for the determination of the value of $F_{p i}$ can be defined as: 


$$
F_{p i}=\left(\alpha_{1}-0.02 \frac{b_{c}}{t_{c}}\right) \frac{2 m_{p l a}}{d^{\prime}}
$$

where

$$
\alpha_{1}=1.11+0.1 \frac{d^{\prime}}{t_{f}}
$$

In situations where restrictions on detailing results in the column face governing the connection moment capacity, alternative expressions which are provided elsewhere [50] can be adopted.

An appropiate representation for the post-yield stiffness of the bolt-row can also be derived. Figure 21 depicts the values of the post-yield stiffness coefficient defined as the ratio between the strain hardening $k_{p i}$ and initial stiffness $k_{i}$ as a function of column face slenderness $b_{c} / t_{c}$. Following a curve fitting procedure as before, a simplified equation for estimating the strain hardening stiffness is suggested as:

$$
k_{p i} / k_{i}=0.0016\left(\frac{b_{c}}{t_{c}}\right)^{1.4}
$$

\subsection{Overall moment-rotation response}

The previous sections provided relationships for determining the stiffness and capacity of the constituent bolt-rows within a top and seat or top, seat and web angle blind-bolted connection. The connection moment-rotation response can now be determined based on such relationships. A simplified component model such as that suggested in Eurocode 3 Part 1.8 [5] is adopted for top and seat angle connections, and the extension proposed by Pucinotti [51] is adopted for top, seat and web angle connections, as indicated in Figure 22b. For simplicity, a pre-defined point of rotation can be assumed at the horizontal leg of the bottom angle for top and seat angle connections. Hence, the initial rotational stiffness of the connection is given by: 


$$
S_{T}=k_{T} y_{T}^{2}
$$

where $k_{T}$ is the stiffness of the top angle bolt-row and $y_{t}$ is the distance between the top angle bolt-row and the horizontal leg of the bottom angle.

On the other hand, when web angles are included, the higher capacities reached and the additional rotational restraint imposed by the web cleats can alter the point of rotation. This effect would be aggravated if the compression contact region is substantially smaller than the tubular column width [27]. A mechanical model that considers the column face compression stiffness $k_{\text {comp }}$ (which in this study was taken equal to the tension stiffness $k_{c f}$ defined in Equation 6), and replaces the web and top angle rows by an equivalent spring with stiffness $k_{e q}$, can be constructed (Figure 22b). In this case, for connections with top, seat and web angle components, the following expression can be derived for $S_{T}[51]$ :

$$
S_{T}=\frac{y_{e q}}{1 / k_{c o m p}+1 / k_{e q}}
$$

in which $k_{e q}$ and $y_{e q}$ are given by:

$$
\begin{gathered}
k_{e q}=\frac{\sum k_{i} y_{i}}{y_{e q}} \\
y_{e q}=\frac{\sum k_{i} y_{i}^{2}}{\sum k_{i} y_{i}}
\end{gathered}
$$

where $k_{i}$ is the stiffness of the $i^{\text {th }}$ bolt-row, and $y_{i}$ defines the location of the bolt-row with reference to the assumed point of rotation.

In the same way, the rotation at the attainment of plastic capacity in the top angle (i.e. $F_{p i}$ 
calculated from Equation 20) will be:

$$
\theta_{p i}=\frac{v_{p i}}{H}
$$

where $H$ is the summation of the beam height ( $D$ in Figure 1$)$ and the angle thickness $t_{f}$, while $v_{p i}=F_{p i} / k_{i}$. Assuming elastic behaviour in the remaining bolt-rows, the plastic moment can be evaluated as:

$$
M_{y}=F_{p i} H+\sum_{j=1}^{n-1} F_{j} y_{j}
$$

where $j$ is the number of remaining bolt-rows and $F_{j}$ is the axial force in the $\mathrm{j}^{\text {th }}$ bolt-row. The bilinear moment-rotation relationships proposed above are compared with experimental results in Figures 23 and 24. Specimen A5.0-G8.8-d65-M and A5.0-G8.8-d65-Y which involved yielding of the column face at an early stage, and Specimen B10-G8.8-d40-M where significant localised deformations occurred in the compression zone of the column, represent undesirable behaviour which does not conform with the assumptions of the proposed simplified expressions and are hence excluded from the comparisons in Figures 23 and 24.

In general, as illustrated in Figures 23 and 24, reasonably good predictions of the response are obtained by the simplified bi-linear model, with more favourable estimations obtained for longer angle gauge distances. The connection initial stiffness is well predicted in all cases, whereas conservative estimates of the capacity are obtained for stiffer angles (shorter gauge distances). The only exceptions are Specimen C10-G10.9-d40-M (in Figure 23) where a discrepancy with the yield capacity of the specimen is evident. This is attributed to the significant slippage of the standard bolts which occurred in this test, an effect which cannot be captured by the simplified model. Accordingly, provisions should be made to limit the extent of slippage in practice to ensure the adequacy of the simplified approach, by comply- 
ing with the conventional range of clearances (e.g. 1 to $2 \mathrm{~mm}$ ) for standard bolts over which these expressions have been validated.

\section{Concluding remarks}

This paper has proposed a detailed mechanical model for blind-bolted angle connections between open beams and tubular columns. The model is based on the component approach and utilises a multi-linear representation in order to trace the full monotonic and cyclic response of top and seat and top, seat and web angle connections. The validity of the model has been assessed against recent experimental results and the detailed model was found to provide reliable predictions of the response for the range of connection configurations considered. In particular, the initial stiffness and capacity are predicted within an accuracy of under $5 \%$ in all cases.

A set of parametric assessments were carried out using the detailed model, with the aim of examining the key factors influencing the behaviour of semi-rigid blind-bolted connections. It was shown that the Hollo-bolt grade, angle thickness, column face flexibility and gauge distance can have a significant influence on the stiffness and capacity of the connections. Particular attention was given to tracing the development of the force and deformation within the blind bolts in order to asses the available reserve of strength as well as to verify serviceability limits. Importantly, it was observed that the improved initial stiffness characteristics of Grade 10.9 Hollo-bolts enable a more consistent definition of the failure mode and can enhance the reliability of blind-bolted connections.

In order to provide preliminary information for the purpose of practical design implementation, simplified expressions for estimating the stiffness and capacity of blind-bolted angle 
connections were proposed based on a data-set generated from the detailed mechanical model and considering the salient parameters that were identified. The suitability of the simplified expressions for representing the connection response was also validated against the experimental results. To this end, this work constitutes a fundamental step towards the provision of codified design procedures for blind-bolted connections.

\section{Acknowledgements}

The financial support of Corus Tubes and CIDECT for the research described in this paper is gratefully acknowledged. The first author would also like to acknowledge the support provided by EPSRC in the UK for his doctoral research studies through a Dorothy Hodgkin Award.

\section{References}

[1] Cao J, Packer J, Kosteski N. Design guidelines for longitudinal plate to HSS connections. Journal of Structural Engineering, American Society of Civil Engineering 1998; 124(7):784-791.

[2] Kosteski N, Packer J. Longitudinal plate and through plate-to-hollow structural section welded connections. Journal of Structural Engineering, American Society of Civil Engineering 2003; 129(4):478-486.

[3] Kosteski N, Packer J. Welded tee to HSS connections. Journal of Structural Engineering, American Society of Civil Engineering 2003; 129(2):151-159.

[4] Kurobane Y. Connections in tubular structures. Progress in Structural Engineering and Materials 2002; $4(1): 35-45$.

[5] CEN. EN 1993-1-8, Eurocode 3: Design provisions of steel structures, part 1.8: Design of joints 2005.

[6] Elnashai A, Elghazouli A, Denesh-Ashtiani F. Response of semirigid steel frames to cyclic and earthquake loads. Journal of Structural Engineering, American Society of Civil Engineering 1998; 124(8):857-867. 
[7] Leon RT, Hoffman JJ, Staeger PE. Partially restrained composite connections - a design guide, steel design guide series 1998.

[8] Elghazouli A. Ductility of frames with semirigid connections. 11th World Conference on Earthquake Engineering, Acapulco, Mexico, 1996.

[9] Garlock M, Ricles J, Sause R. Cyclic load tests and analysis of bolted top and seat angle connection. Journal of Structural Engineering, American Society of Civil Engineering 2003; 129(12):1615-1625.

[10] Kukreti A, Abolmaali A. Moment-rotation hysteresis behavior of top and seat angle steel frame connections. Journal of Structural Engineering, American Society of Civil Engineering 1999; 8:810-820.

[11] Mander J, Stuart S, Pekcan G. Low-cycle fatigue behavior of semirigid top and seat angle connections. Engineering Journal 1994; 31(3):111-122.

[12] Shen J, Astaneh-Asl A. Hysteretic behavior of bolted angle connections. Journal of Constructional Steel Research 1999; 51:201-218.

[13] Banks G. Flowdrilling for tubular structures. Proceedings of the Fifth International Conference on Tubular Structures, Nottingham, 1993.

[14] Ballerini M, Piazza M, Bozzo E, Occhi F. Shear capacity of blind bolted connections for RHS steel structural elements. Proceedings of the Seventh International Conference on Tubular Structures, Kansas, $1996 ; 99-106$.

[15] France J, Davison B, Kirby P. Strength and rotational response of moment connections to tubular columns using flowdrill connectors. Journal of Constructional Steel Research 1999; 50:1-14.

[16] France J, Davison B, Kirby P. Strength and rotational stiffness of simple connections to tubular columns using flowdrill connectors. Journal of Constructional Steel Research 1999; 50:15-34.

[17] Occhi F. Hollow section connections using (hollowfast) hollowbolt expansion bolting, second interim report 6G-16/95. Technical Report, Sidercad, Italy 1995.

[18] Klippel S. Recent design developments with blind mechanically operated bolt systems for use with hollow section steelwork. Journal of Constructional Steel Research 1998; 46:267-268.

[19] Dutta D, Wardenier J, Yeomans N, Sakae K, Bucak O, Packer J. Fabrication, assemblage et montage des structures en profils creux. Serie CIDECT Guide de dimensionnement \%. TUV-Verlag, Germany, 1999.

[20] Banks G. Hollowbolt joint shear tests project no S2860. Technical Report, British Steel Plc., Swinden Technology Centre, Rotherham 1997.

[21] Lindapter International. Type HB Hollo-bolt for blind connection to structural steel and structural 
tubes 1995.

[22] France J. Bolted connections between open section beams and box columns. PhD Thesis, Department of Civil and Structural Engineering, University of Sheffield, UK 1997.

[23] Barnett T. The behaviour of a blind bolt for moment resisting connections in hollow steel sections. PhD Thesis, Department of Civil Engineering, University of Nottingham, UK 2001.

[24] Wang J, Han L, Uy B. Behaviour of flush end plate joints to concrete-filled steel tubular columns. Journal of Constructional Steel Research 2009; 65(4):925-939.

[25] Barnett T, Tizani W, Nethercot D. The practice of blind bolting connections to structural hollow sections: A review. Steel and Composite Structures 2001; 1:1-16.

[26] Barnett T, Tizani W, Nethercot D. Blind bolted moment resisting connections to structural hollow sections. Connections in Steel Structures IV, Virginia, 2000.

[27] Elghazouli A, Málaga-Chuquitaype C, Castro J, Orton A. Experimental monotonic and cyclic behaviour of blind-bolted angle connections. Engineering Structures 2009; 31(11):2540-2553.

[28] Agerskov H. High strength bolted connections subjected to prying. Journal of the Structural Division, American Society of Civil Engineering 1976; 102(1):161-175.

[29] Yee Y, Melchers R. Moment-rotation curves for bolted connections. Journal of Structural Engineering, American Society of Civil Engineering 1986; 112(3):615-635.

[30] Jaspart J. Étude de la semi-rigidité des noeuds pourter-colonne et son influence sur la résistance et al stabilit/'e des ossatures en acier. PhD Thesis, Faculty of Applied Sciences, University of Liege, Belgium 1991.

[31] Faella C, Piluso V, Rizanno G. Structural steel semirigid connections: Theory, design and software. CRC Press, Florida, USA, 2000.

[32] Swanson J, Leon RT. Stiffness modeling of bolted T-stub connection components. Journal of Structural Engineering, American Society of Civil Engineering 2001; 127(5):498-505.

[33] Lemonis M, Gantes C. Incremental modeling of T-stub connections. Journal of Materials and Structures 2006; 1(7):1135-1159.

[34] Kishi N, Chen W. Moment-rotation relation of semi-rigid connections with angles. Journal of Structural Engineering, American Society of Civil Engineering 1990; 116(7):1813-1834.

[35] Kishi N, Ahmed A, Yabuki N. Nonlinear finite element analyses of top and seat-angle with double webangle connections. International Journal of Structural Engineering and Mechanics 2001; 12:201-214.

[36] De Stefano M, De Luca A, Astaneh-Asl A. Modeling of cyclic moment-rotation response of double- 
angle connections. Journal of Structural Engineering, American Society of Civil Engineering 1993; 120(1):212-229.

[37] Shen J, Astaneh-Asl A. Hysteretic model of bolted angle connections. Journal of Constructional Steel Research 2000; 54:317-343.

[38] Ghobarah A, Mourand S, Korol R. Moment-rotation relationship of blind bolted connections to tubular columns. Journal of Constructional Steel Research 1996; 50:1-14.

[39] Silva L, Neves L, Gomes F. Rotational stiffness of rectangular hollow sections composite joints. Journal of Structural Engineering, American Society of Civil Engineering 2003; 129:487-494.

[40] Yeomans N. Guide on the use of bolts, single sided (blind) bolting systems. Serie CIDECT Construction with Hollow Sections. ECCS-TC 10-01-WG3/188, 2002.

[41] Kurobane Y, Packer J, Wardenier J, Yeomans N. Design guide for structural hollow section column connections. Serie CIDECT Construction with Hollow Sections. TUV-Verlag, Germany, 2004.

[42] AISC. Hollow structural section connections manual. chicago, illinois, usa, american institute of steel construction 1997.

[43] ECCS B European Convention for Constructional Steelwork. Recommended testing procedure for assessing the behaviour of structural steel elements under cyclic loads 1986.

[44] Heidarpour A, Bradford M. Behaviour of a T-stub assembly in steel beam-to-column connections at elevated temperatures. Engineering Structures 2008; 30(10):2893-2899.

[45] Struik J, de Black J. Tests on bolted T-stubs with respect to bolted beam to column connections. Report 6-69-13. Technical Report, Stevin Laboratory, Delft University of Technology, The Netherlands 1969.

[46] Málaga-Chuquitaype C. Seismic behaviour and design of steel frames incorporating tubular members. PhD Thesis, Department of Civil and Environmental Engineering, Imperial College London, London, UK 2010 (In preparation).

[47] Gomes F. Etat limite ultime de la résistance de l'ame d'une colonne dans un assemblage semi-rigide d'axe faible. rapport interne 203. Technical Report, University of Liege 1990.

[48] De Stefano M, Astaneh-Asl A. Axial force-displacement behaviour of steel double angles. Journal of Constructional Steel Research 1991; 20:161-181.

[49] MATLAB. 7.3 Getting Started Guide, The MathWorks Inc., USA 2006.

[50] Neves LF. Comportamento monotnico e cclico de ligacoes de eixo fraco e tubulares em estruturas metalicas e mistas aco-betao. [in Portuguese]. PhD Thesis, University of Coimbra, Portugal 2004. 
[51] Pucinotti R. Top-and-seat and web angle connections: prediction via mechanical model. Journal of Constructional Steel Research 2001; 57:661-694. 
Appendix A. Stiffness at different deformation stages

$$
\begin{aligned}
& k_{\text {Iee }}=\left(k_{A}+\frac{1}{k_{t}}+\frac{1}{k_{\text {slip }}}\right)^{-1} \quad k_{\text {Iep }}=\left(k_{B}+\frac{1}{k_{t}}+\frac{1}{k_{\text {slip }}}\right)^{-1} \\
& k_{\text {Ipe }}=\left(k_{C}+\frac{1}{k_{t}}+\frac{1}{k_{\text {slip }}}\right)^{-1} \quad k_{\text {Ipp }}=\left(k_{D}+\frac{1}{k_{t}}+\frac{1}{k_{\text {slip }}}\right)^{-1} \\
& k_{\text {Iey }}=\left(\frac{k_{\text {Iee }}+3 k_{\text {Iep }}}{4}\right) \quad k_{\text {Iye }}=\left(\frac{k_{\text {Iee }}+3 k_{\text {Ipe }}}{4}\right) \\
& k_{\text {Iyy }}=\left(\frac{k_{\text {Iee }}+3 k_{\text {Ipp }}}{4}\right) \quad k_{\text {Iyp }}=\left(\frac{k_{I e p}+3 k_{I p p}}{4}\right) \\
& k_{I p y}=\left(\frac{k_{I p e}+3 k_{I p p}}{4}\right) \\
& k_{A}=\frac{\left.12 E I\left(\left(-3 d^{\prime 4} k_{\alpha}-d^{\prime 3} k_{\alpha} c^{\prime}\right) c^{\prime 3}+\left(72 d^{\prime 4}+\left(-3 d^{\prime 3}+\beta_{1}\right) c^{\prime}\right) c^{\prime}\right) E I\right)}{-\left(\left(3 d^{\prime 4} k_{\alpha}+4 d^{\prime 3} k_{\alpha} c^{\prime}\right) c^{\prime 3}-\beta_{4}+\left(3\left(d^{\prime}-3 c^{\prime}\right)^{3}+60 c^{\prime 4}\right) E I d^{\prime 3}\right.} \\
& k_{B}=\frac{12 E I\left(\beta_{3} c^{\prime}+\left(\left(72 d^{\prime 5} E_{s h} I / t_{f}+\left(-3 d^{\prime 4} E_{s h} I / t_{f}+\beta_{2} c^{\prime}\right) c^{\prime}\right) E+\left(72 d^{\prime 4}+\beta_{1} c^{2}\right) E^{2} I\right) I\right)}{d^{\prime 3}\left(\left(-3 d^{\prime 5} E_{s h} I / t_{f} k_{\alpha}-4 d^{\prime 4} E_{s h} I / t_{f} k_{\alpha} c^{\prime}\right) c^{\prime 3}+\beta_{5}+\beta_{6}\right.} \\
& k_{C}= \\
& \frac{3 E I\left(-d^{\prime 4} c^{\prime 4} E_{s h} I / t_{f} k_{\alpha}+\left(\left(-3 d^{\prime 4} E_{s h} I / t_{f}-3 d^{\prime 4} k_{\alpha} c^{\prime 2}\right) c^{\prime} E+\left(72 c^{\prime 4}+\left(\beta_{1}\right) c^{\prime 2}\right) E^{2} I\right) I\right)}{d^{\prime 3}\left(-d^{\prime 4} a^{4} E_{s h} I / t_{f} k_{\alpha}+\left(\left(-3 d^{\prime 4} E_{s h} I / t_{f}+\left(-3 d^{\prime 4} k_{\alpha}+\left(-3 d^{\prime} E_{s h} I / t_{f}-3 d^{\prime 3} k_{\alpha}\right) c^{\prime}\right) c^{\prime 2}\right) c^{\prime} E+\beta_{4} I\right)\right.} \\
& k_{D}= \\
& k_{\alpha}=\left(\frac{1}{k_{c f}}+\frac{1}{k_{H b}}\right)^{-1} \\
& \beta_{1}=144 c^{2}-216 d^{\prime 2} \\
& \beta_{2}=-216 d^{\prime 3} E_{s h} I / t_{f}+\left(-3 d^{\prime 4} k_{\alpha}+144 b E_{s h} I / t_{f} c^{\prime}\right) c^{\prime} \\
& \beta_{3}=-3 d^{\prime 5} c^{\prime 2} E_{s h} I / t_{f} k_{\alpha}-d^{\prime 4} E_{s h} I / t_{f} k_{\alpha} c^{\prime 3} \\
& \left.\beta_{4}=72 d^{\prime 4}+\left(-9 d^{\prime 3}+\left(-162 d^{\prime 2}+\left(-9 d^{\prime}+72 c^{\prime}\right) c^{\prime}\right) c^{\prime}\right) c^{\prime}\right) E^{2} I \\
& \beta_{5}=E_{s h} I / t_{f} b\left(72 d^{\prime 4}-E\left(24 d^{\prime 3}+108 d^{\prime 2} c^{\prime}+12 d^{\prime 3} c^{\prime 2} k_{\alpha}+36 d^{\prime} c^{\prime 3}+12 d^{\prime 2} k_{\alpha}+12\right)\right)
\end{aligned}
$$




$$
\left.\left.\beta_{6}=288 d^{\prime 4}+\left(-36 d^{\prime 3}+\left(-648 d^{\prime 2}+\left(-36 d^{\prime}+288 c^{\prime}\right) c^{\prime}\right) c^{\prime}\right) c^{\prime}\right) E^{2} I\right) I
$$


Table 1: Summary of test programme

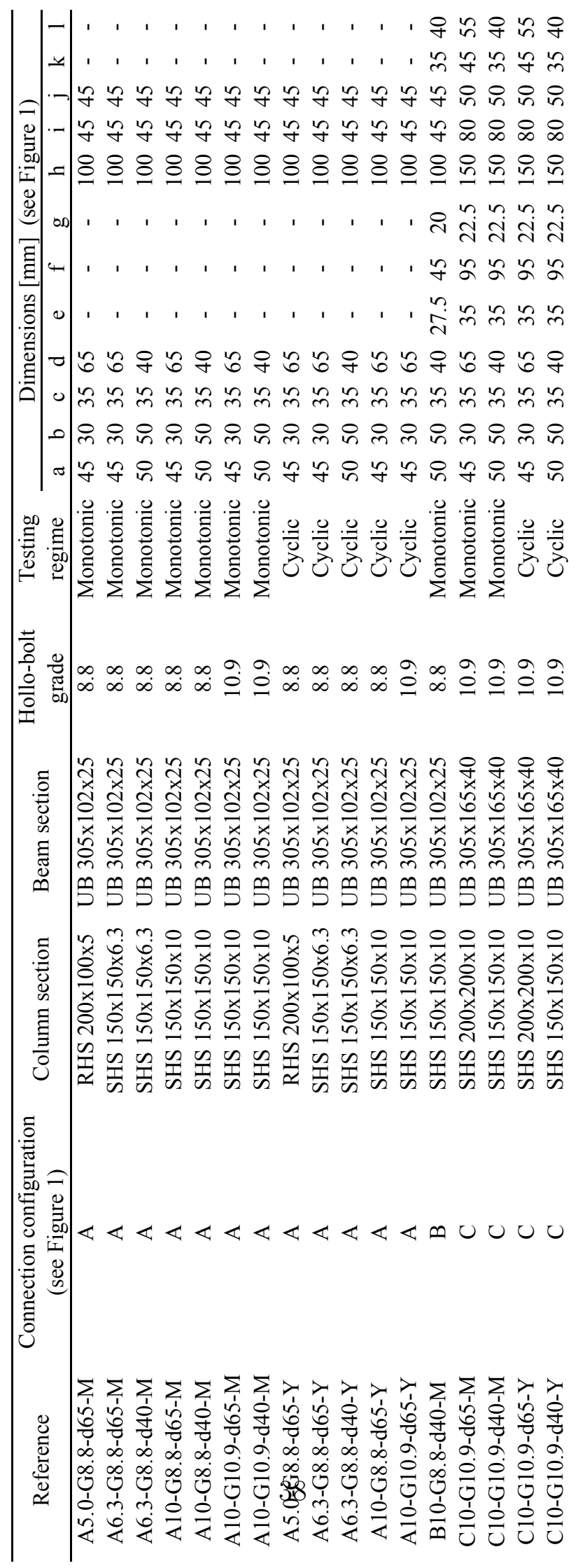


Table 2: Hollo-bolt axial force-displacement relationships

\begin{tabular}{cccc}
\hline \multicolumn{4}{c}{ Hollo-bolt grade } \\
\hline $\begin{array}{c}\text { 8.8 } \\
\text { Displacement } \\
{[\mathrm{mm}]}\end{array}$ & $\begin{array}{c}\text { Force } \\
{[\mathrm{kN}]}\end{array}$ & $\begin{array}{c}\text { Displacement } \\
{[\mathrm{mm}]}\end{array}$ & $\begin{array}{c}\text { Force } \\
{[\mathrm{kN}]}\end{array}$ \\
\hline 0.0 & 0 & 0.0 & 0 \\
0.2 & 32 & 0.4 & 78 \\
4.0 & 88 & 2.6 & 100 \\
7.6 & 115 & 4.5 & 108
\end{tabular}




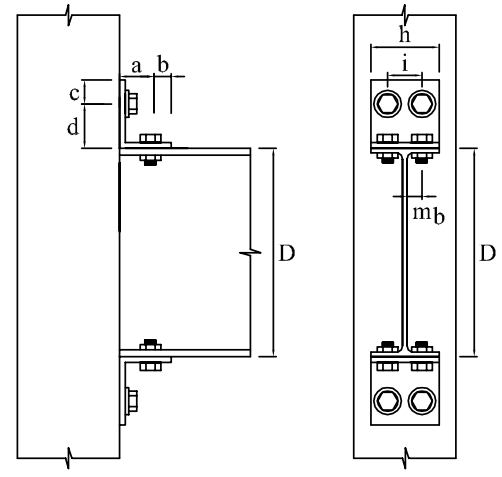

(a) Connection Type A

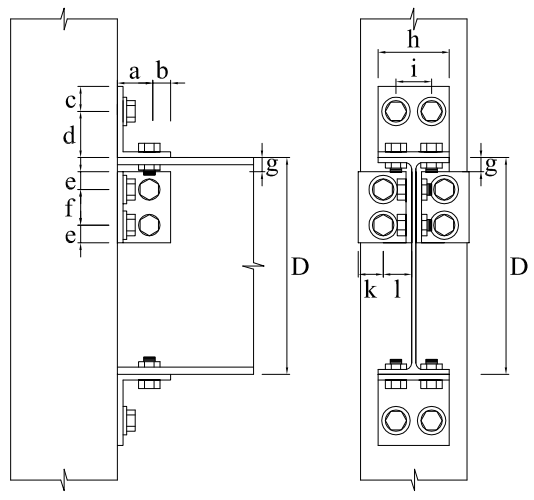

(b) Connection Type B

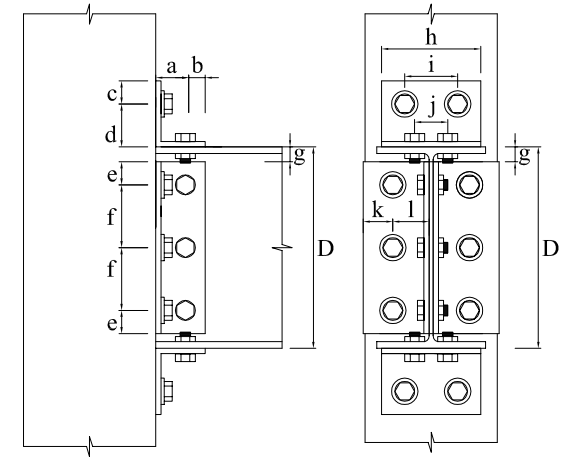

(c) Connection Type C

Figure 1: Details of connection configurations 


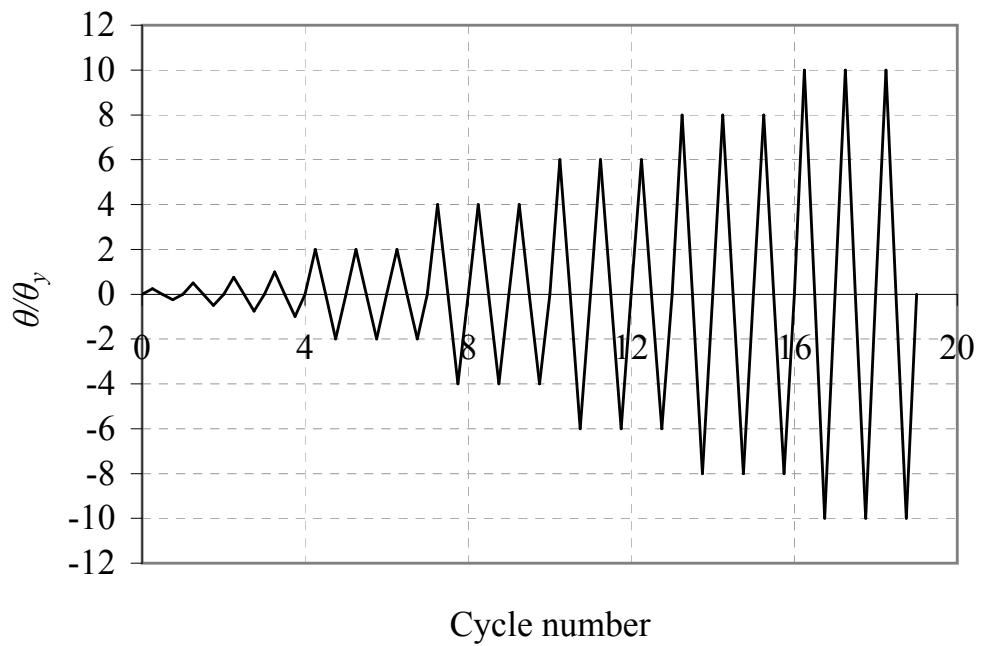

Figure 2: Loading protocol considered in the cyclic tests [43]. 


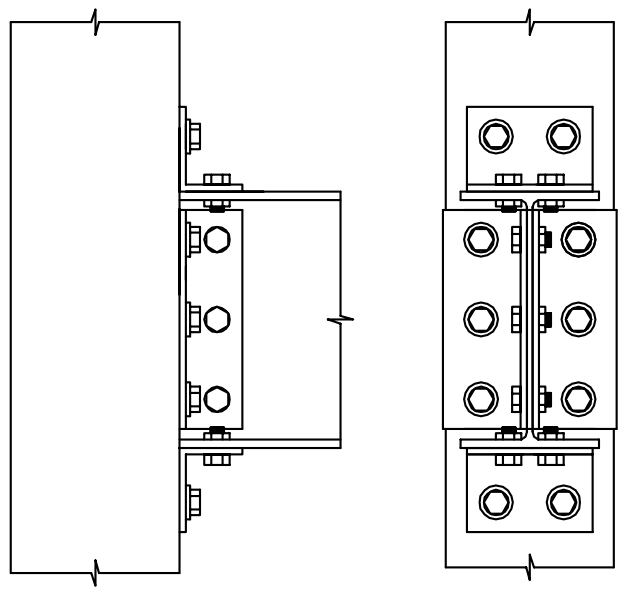

(a) Connection configuration

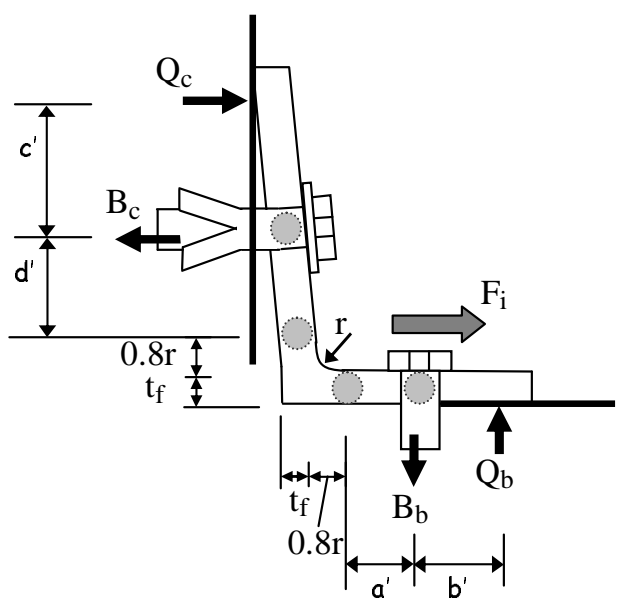

(c) Geometric characteristics of angle model

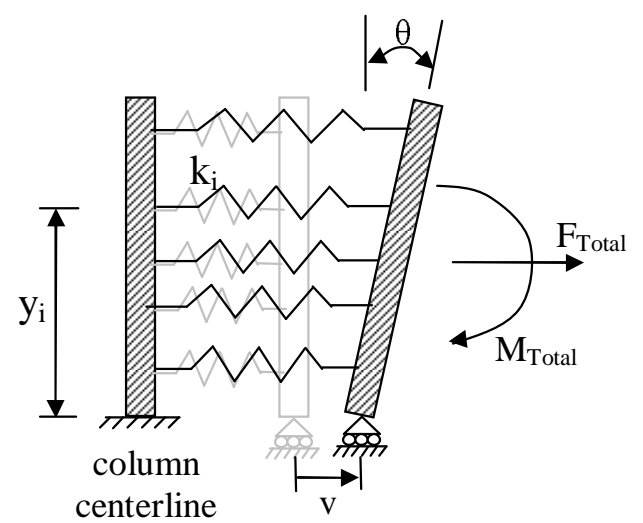

(b) Mechanical model

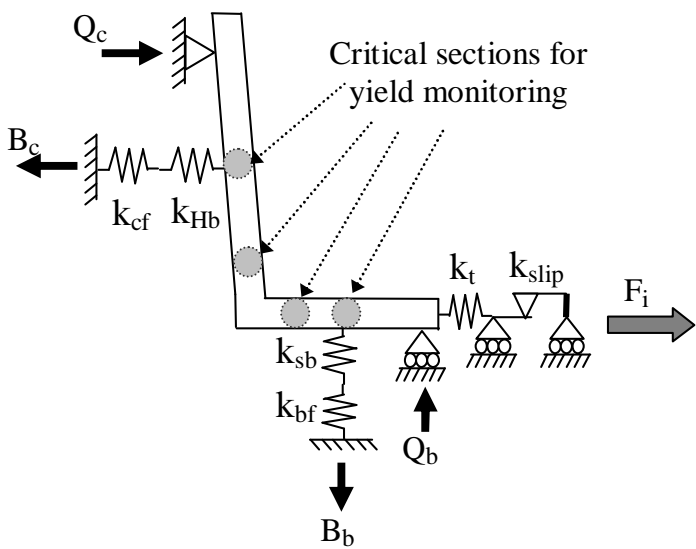

(d) Bolt-row stiffness component $\left(k_{i}\right)$

Figure 3: Mechanical model for angle connections.

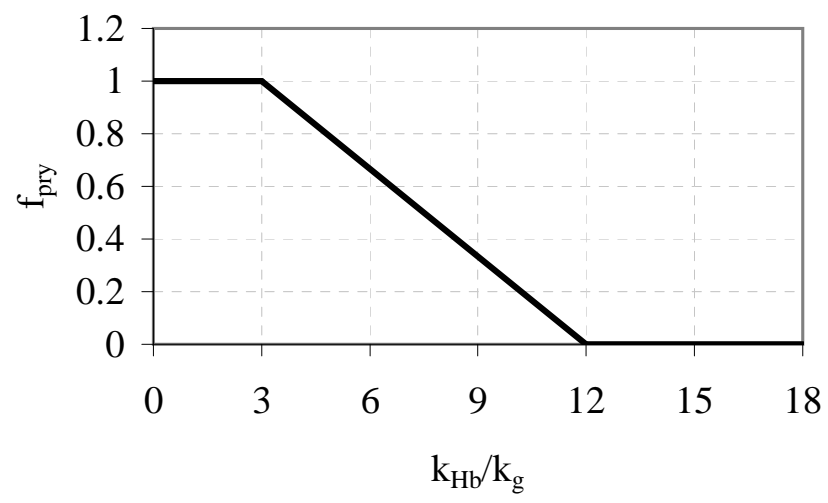

Figure 4: Value of factor $f_{\text {pry }}$ in Equation 3 as a function of the Hollo-bolt relative stiffness 


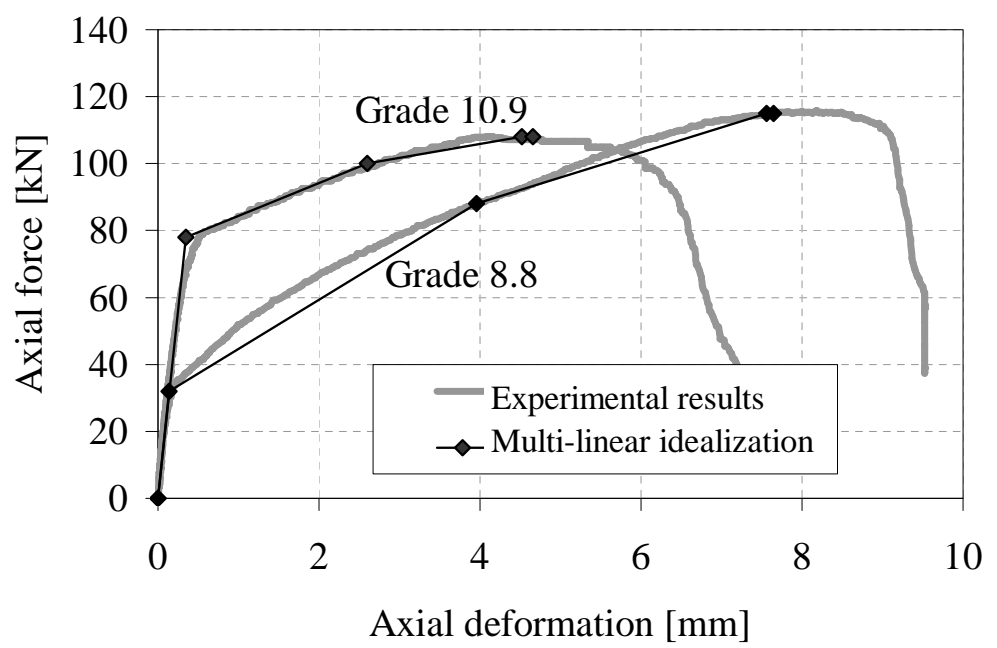

Figure 5: Axial response of Hollo-bolts 


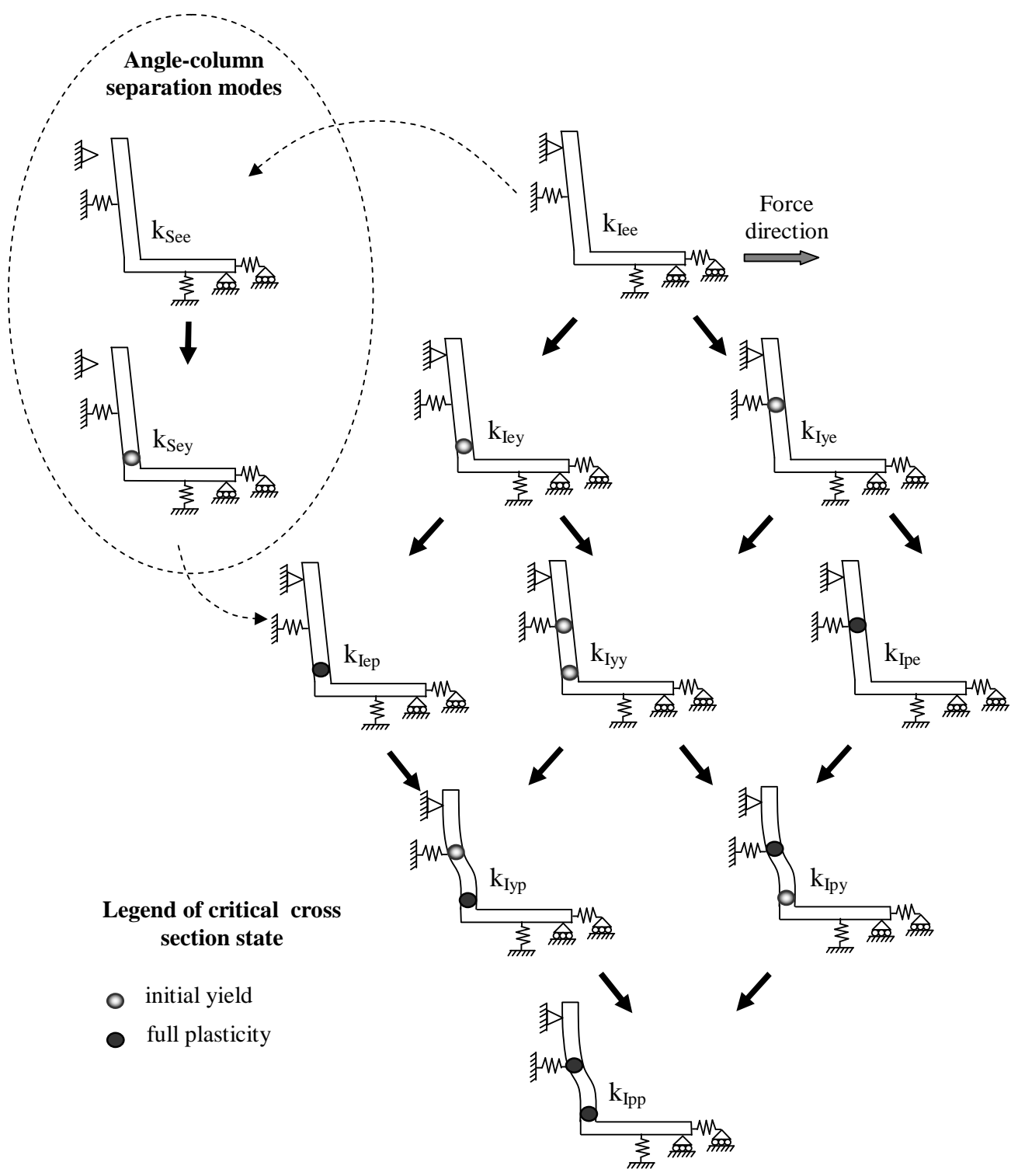

Figure 6: Schematic representation of the decision tree used for the mechanical model. (Phase I) 

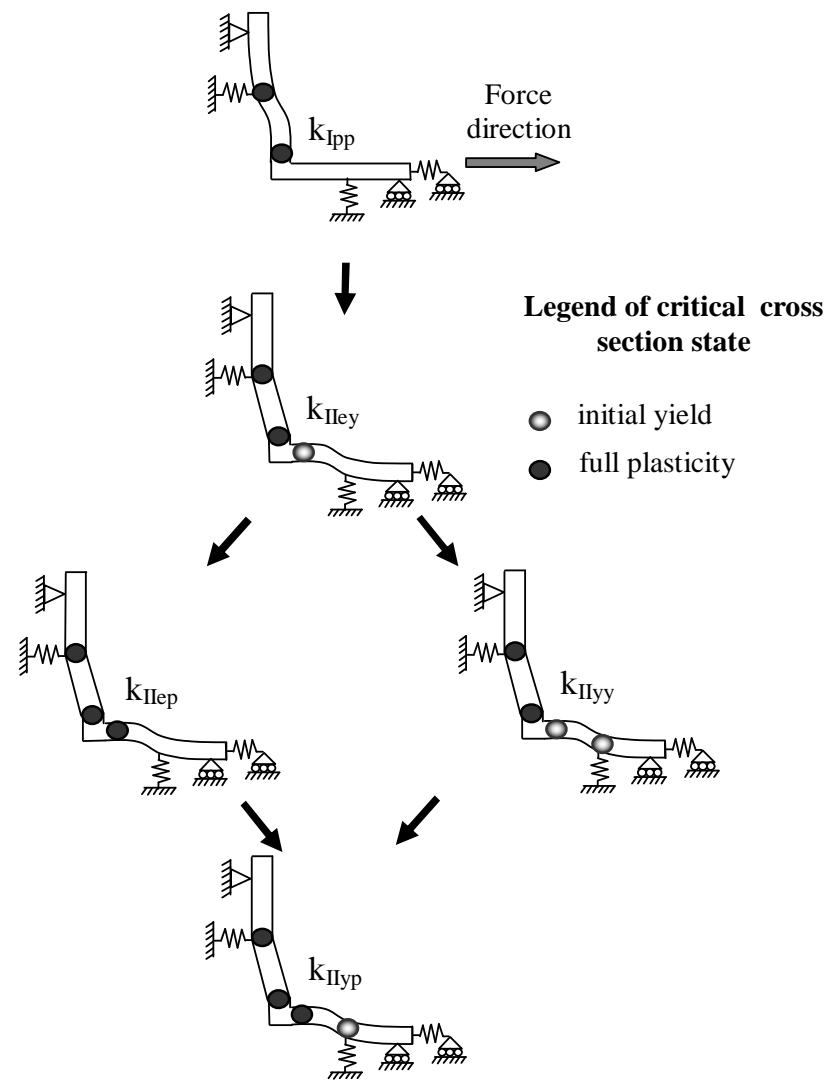

Figure 7: Schematic representation of the decision tree used for the mechanical model. (Phase II)

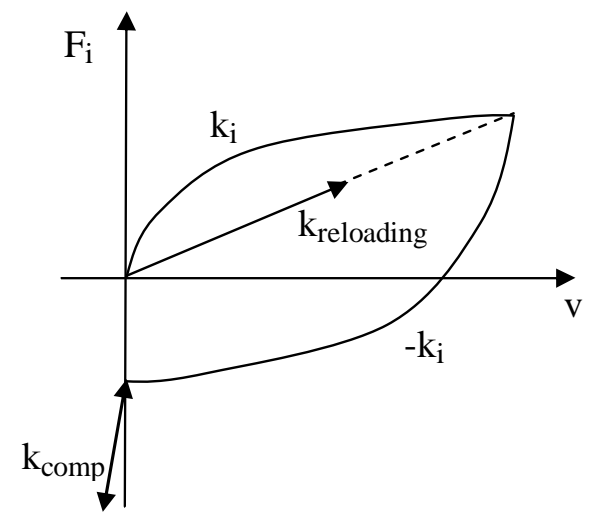

Figure 8: Hysteretic load-displacement response of bolt-row under cyclic loading. 


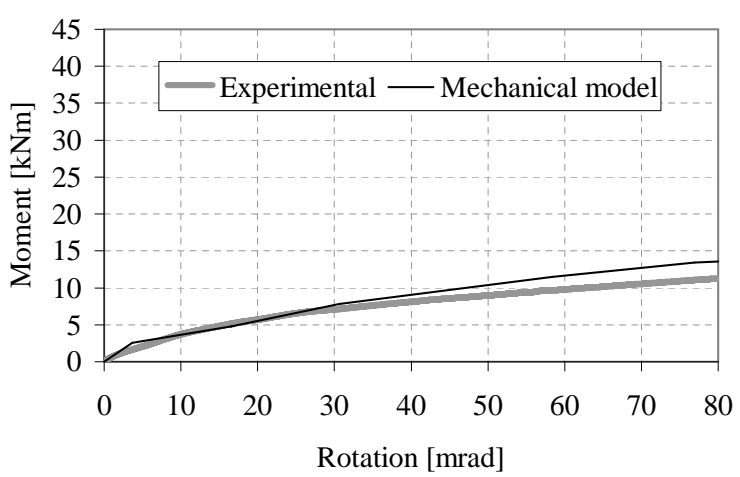

(a) Specimen A5.0-G8.8-d65-M

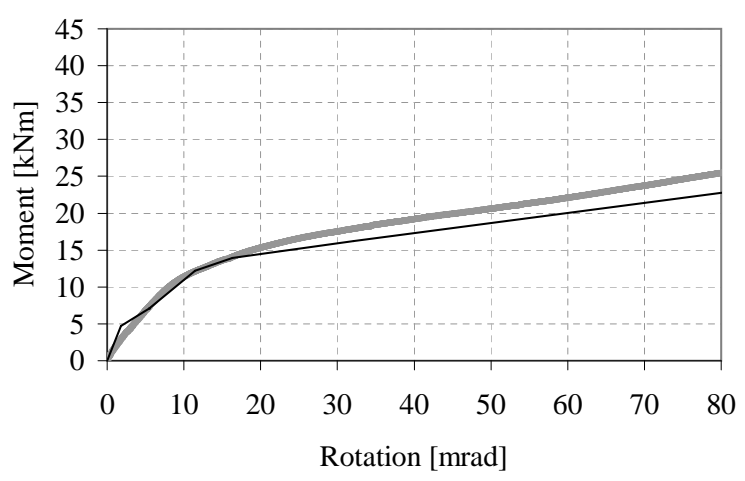

(c) Specimen A6.3-G8.8-d40-M

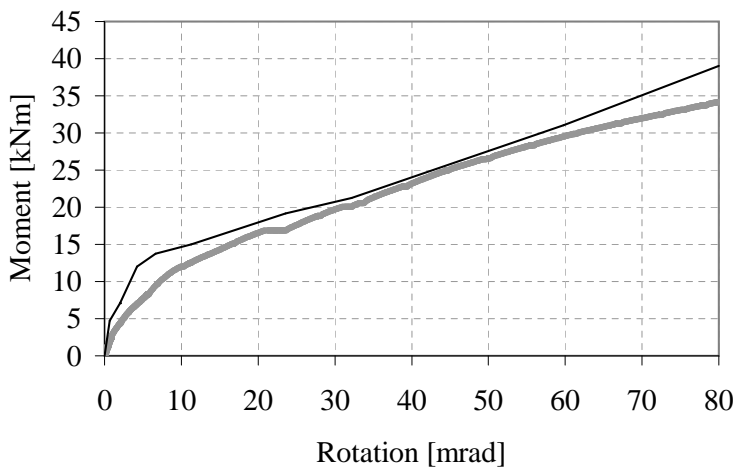

(e) Specimen A10-G8.8-d40-M

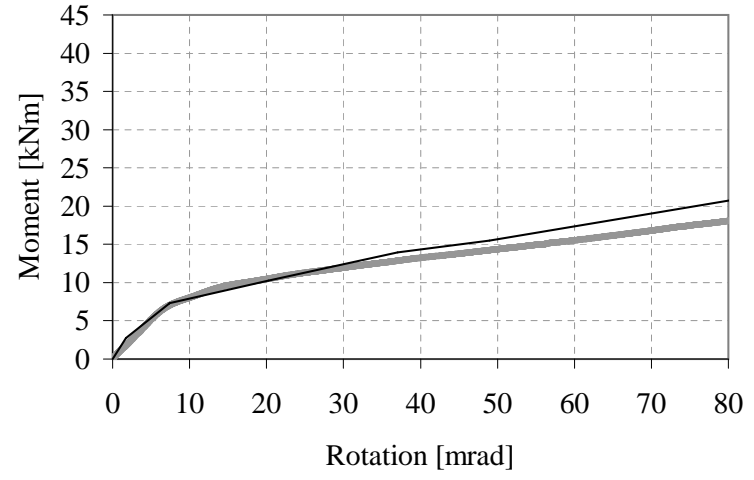

(b) Specimen A6.3-G8.8-d65-M

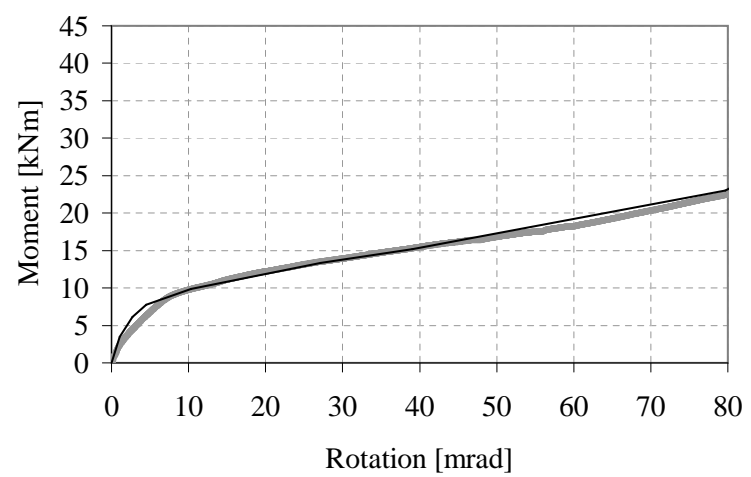

(d) Specimen A10-G8.8-d65-M

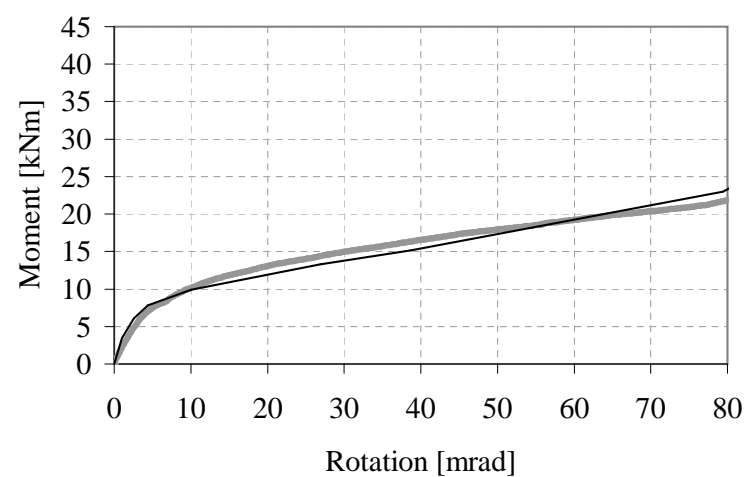

(f) Specimen A10-G10.9-d65-M

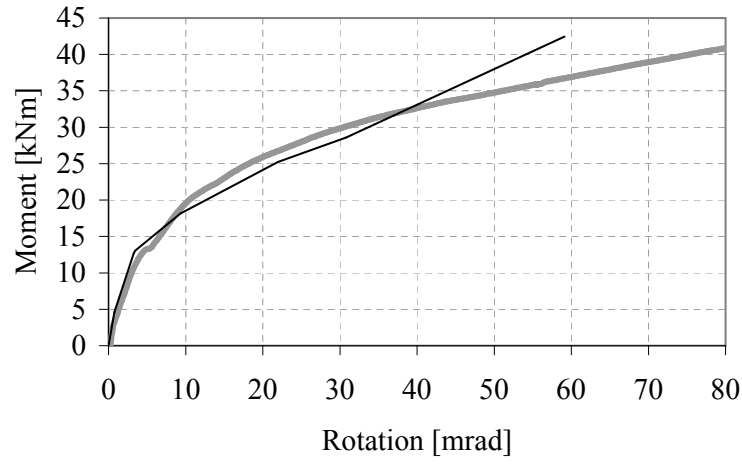

(g) Specimen A10-G10.9-d40-M

46

Figure 9: Comparison of experimental and analytical response of top and seat angle connections under monotonic loading. 


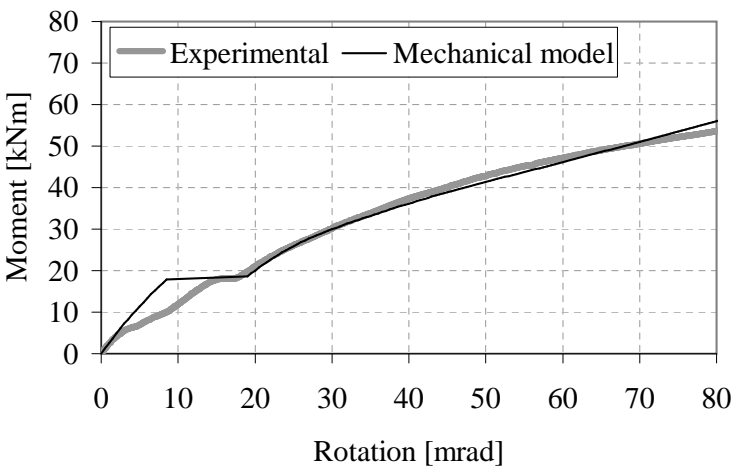

(a) Specimen B10-G8.8-d40-M

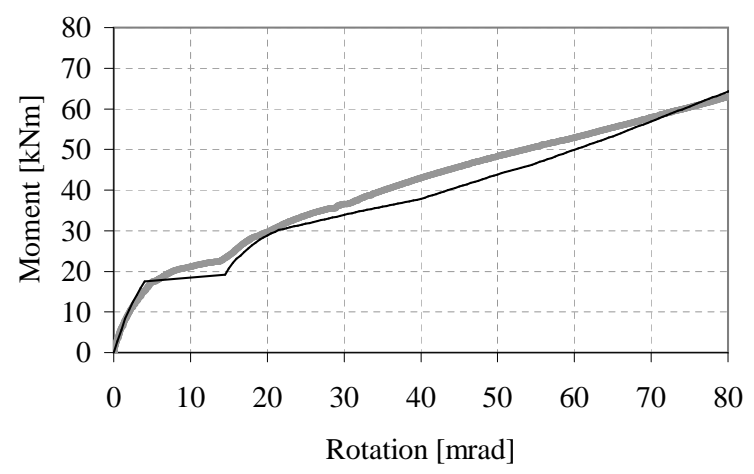

(b) Specimen C10-G10.9-d65-M

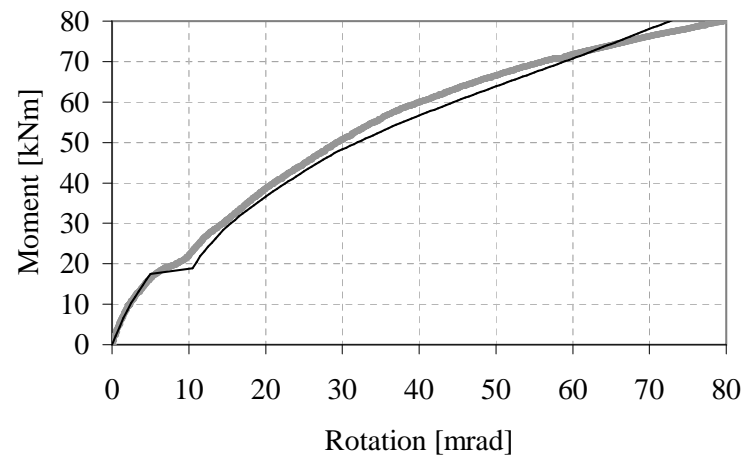

(c) Specimen C10-G10.9-d40-M

Figure 10: Comparison of experimental and analytical response of top, seat and web angle connections under monotonic loading. 


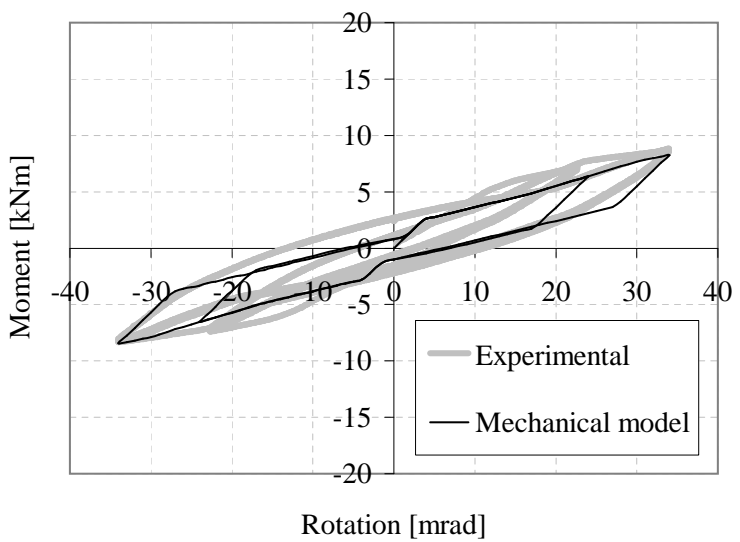

(a) Specimen A5.0-G8.8-d65-Y

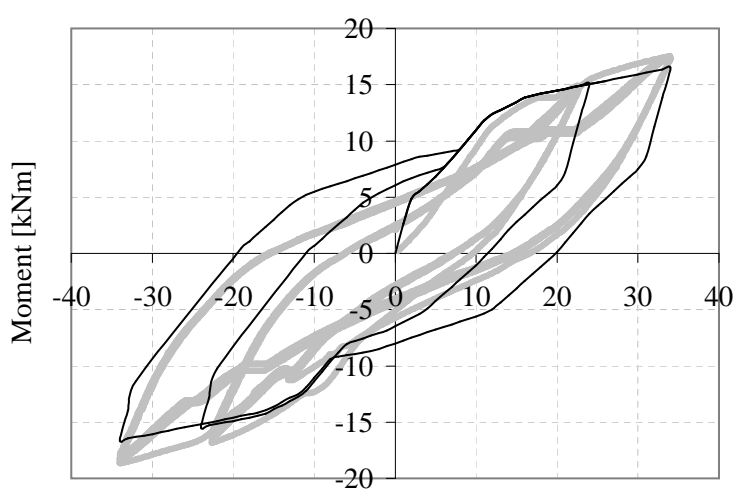

Rotation [mrad]

(c) Specimen A6.3-G8.8-d40-Y

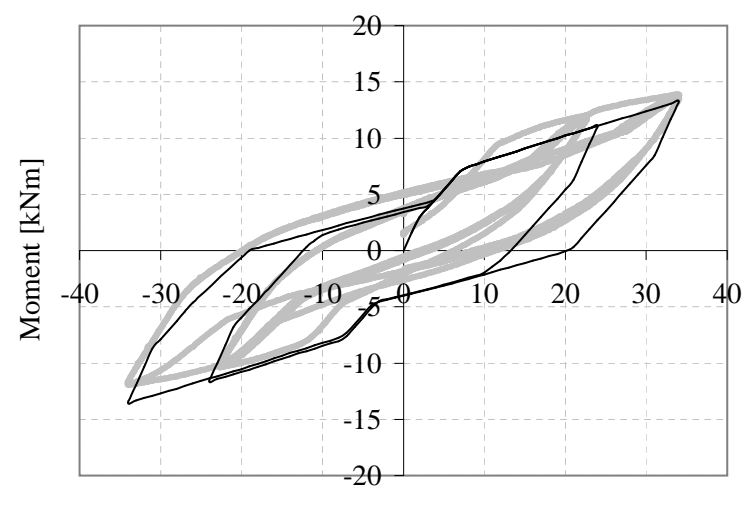

Rotation [mrad]

(b) Specimen A6.3-G8.8-d65-Y

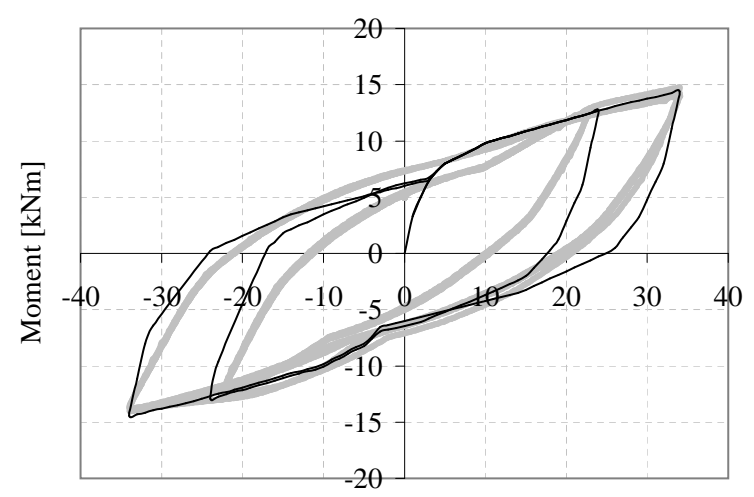

Rotation [mrad]

(d) Specimen A10-G8.8-d65-Y

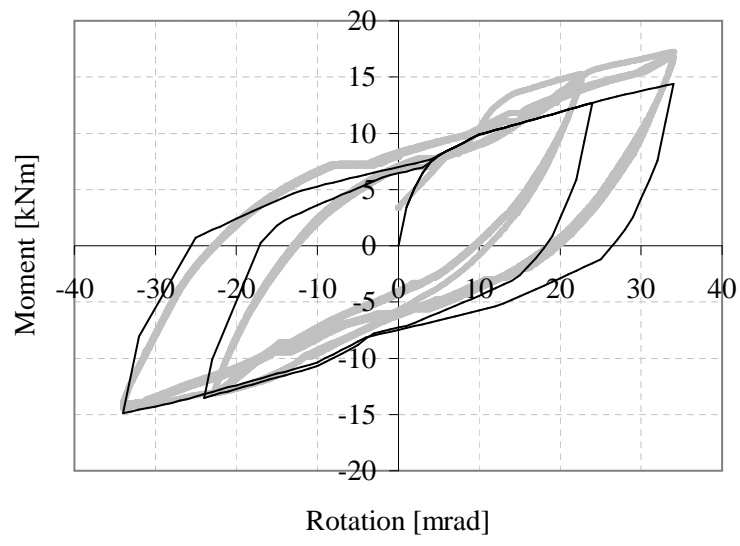

(e) Specimen A10-G10.9-d65-Y

Figure 11: Comparison of experimental and analytical response of top and seat angle connections under cyclic loading. 


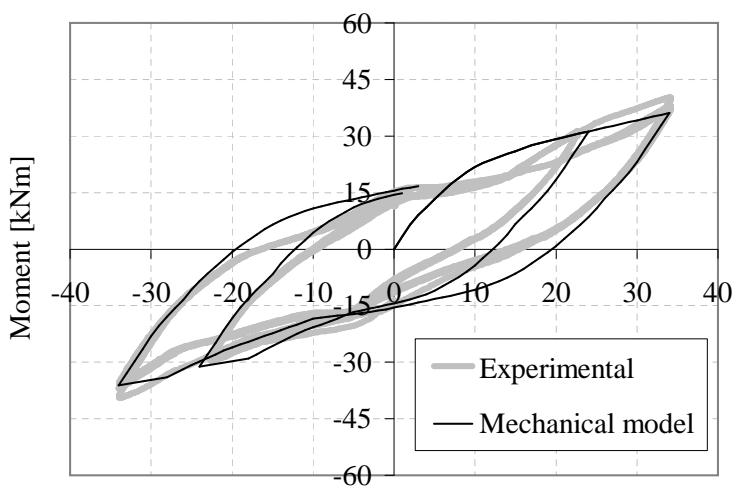

Rotation [mrad]

(a) Specimen C10-G10.9-d65-Y

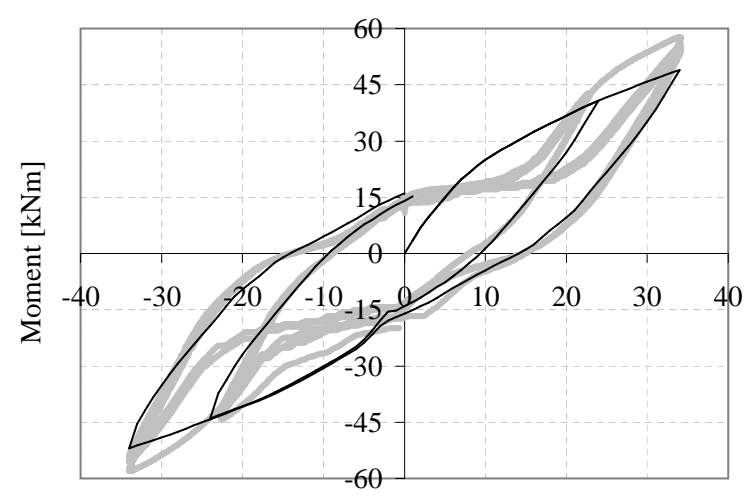

Rotation [mrad]

(b) Specimen C10-G10.8-d40-Y

Figure 12: Comparison of experimental and analytical response of top, seat and web angle connections under cyclic loading.

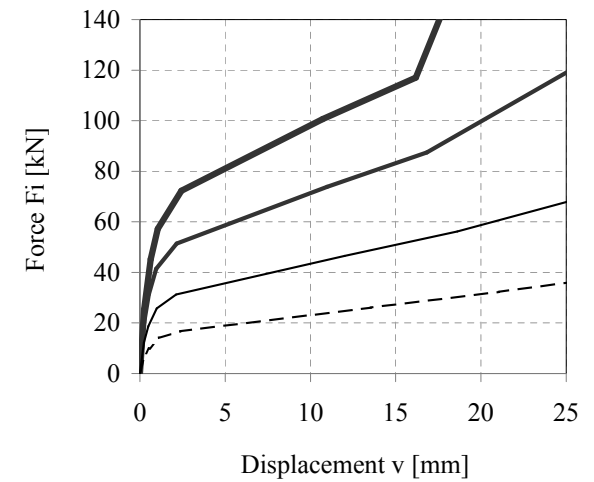

(a) Force displacement relationship in the boltrow

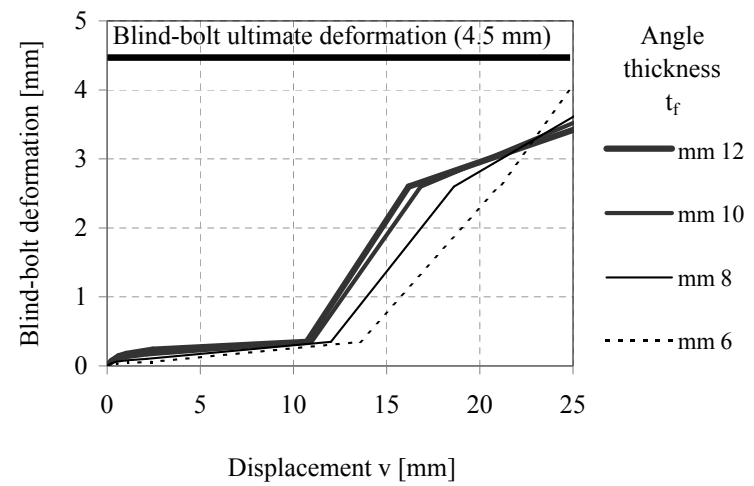

(b) Hollo-bolt separation versus total displacement at the bolt-row

Figure 13: Influence of angle thickness for Grade 10.9 Hollo-bolts

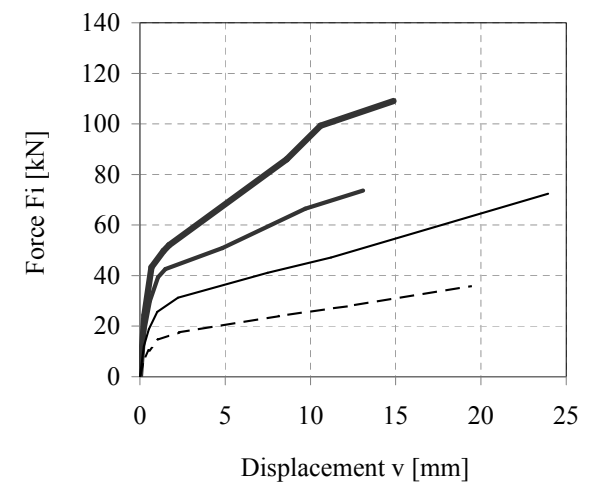

(a) Force displacement relationship in the boltrow

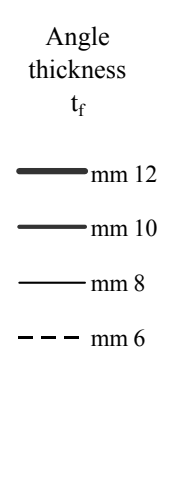

.

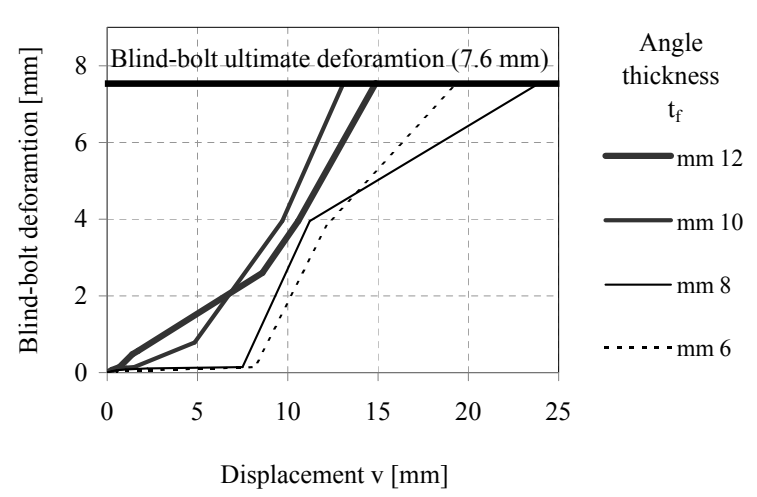

(b) Hollo-bolt separation versus total displacement at the bolt-row

Figure 14: Influence of angle thickness for Grade 8.8 Hollo-bolts 


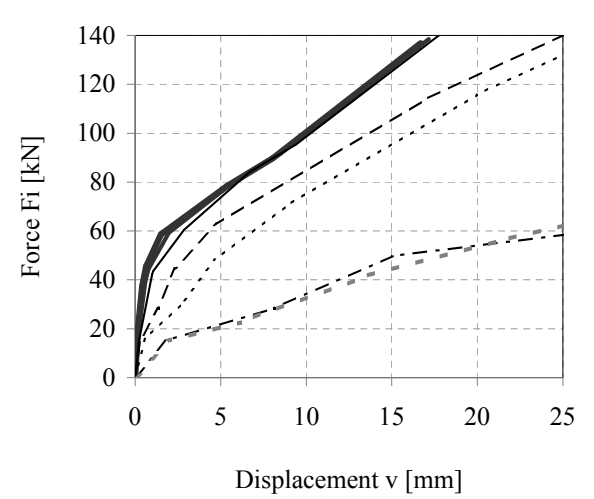

(a) Force displacement relationship in the boltrow
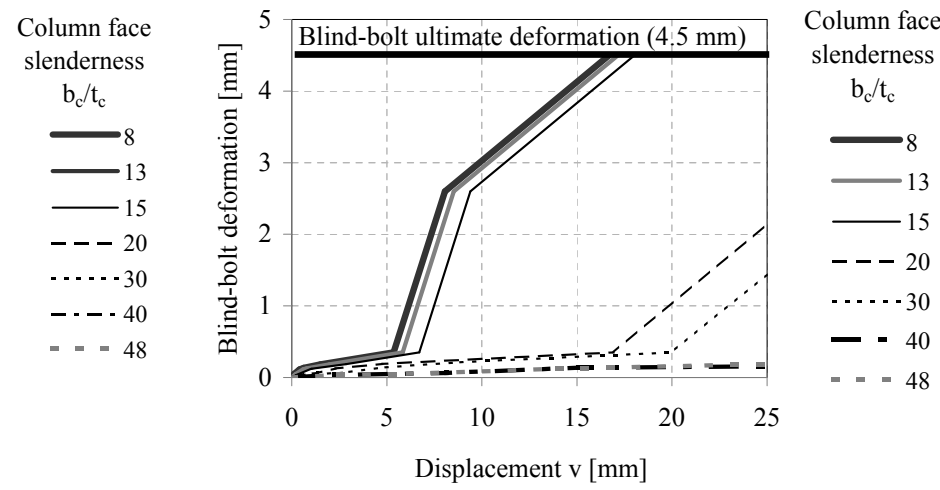

(b) Hollo-bolt separation versus total displacement at the bolt-row

Figure 15: Influence of column face slenderness $\left(b_{c} / t_{c}\right)$ for Grade 10.9 Hollo-bolts

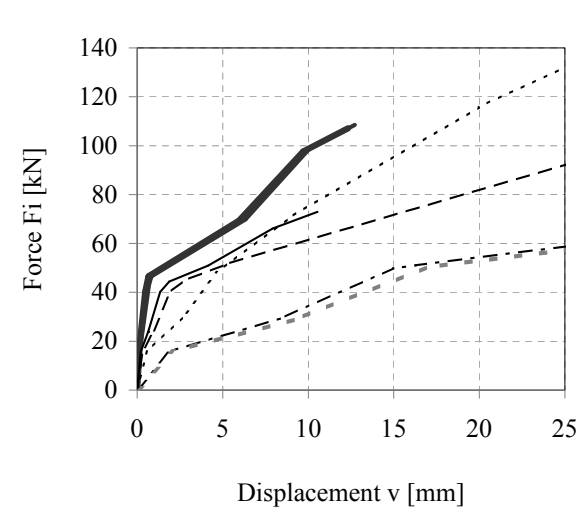

(a) Force displacement relationship in the boltrow

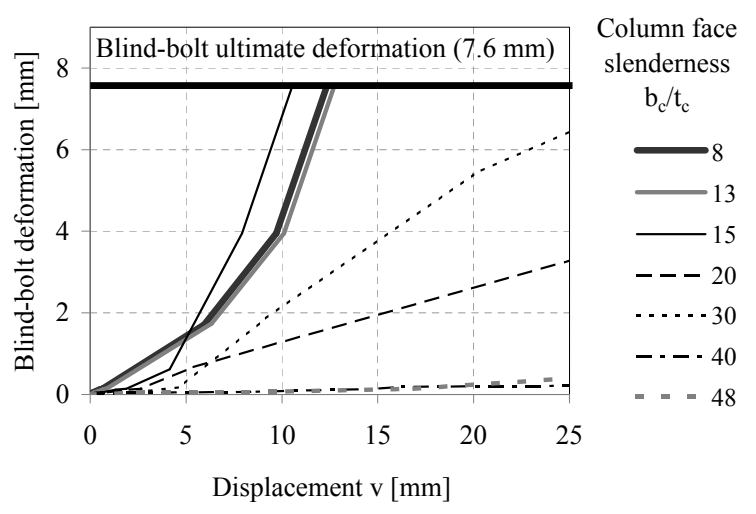

(b) Hollo-bolt separation versus total displacement at the bolt-row

Figure 16: Influence of column face slenderness $\left(b_{c} / t_{c}\right)$ for Grade 8.8 Hollo-bolts

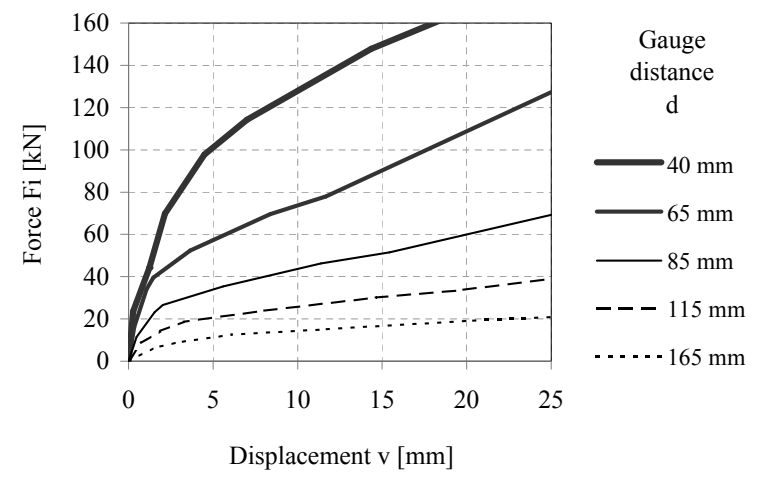

(a) Force displacement relationship in the boltrow

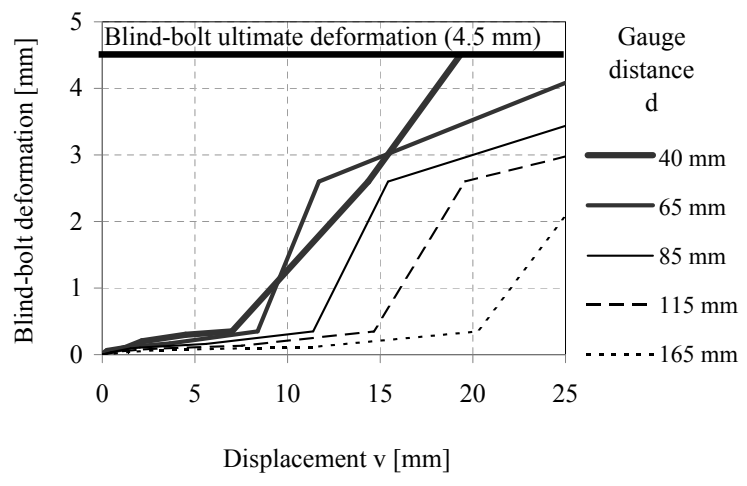

(b) Hollo-bolt separation versus total displacement at the bolt-row

Figure 17: Influence of gauge distance $d$ for Grade 10.9 bolts 


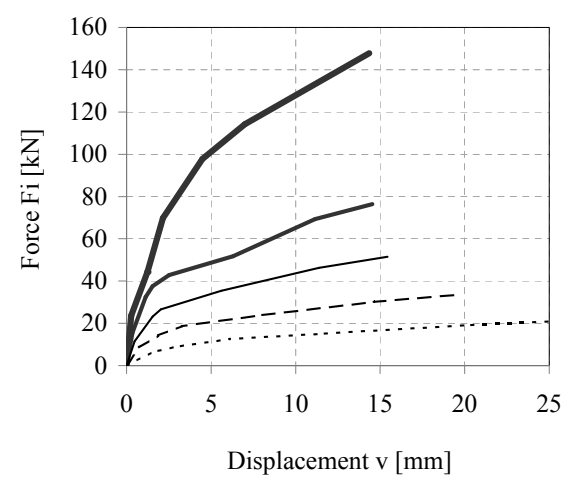

(a) Force displacement relationship in the boltrow

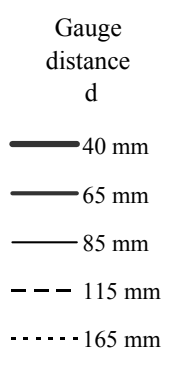

Figure 18: Influence of gauge distance $d$ for Grade 8.8 bolts

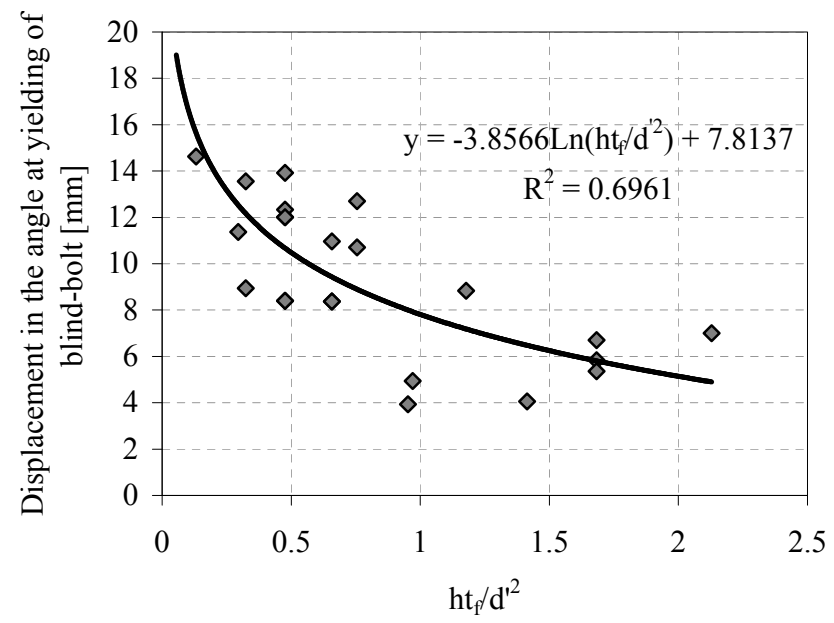

Figure 19: Total bolt-row displacement at which blind-bolt yield would be expected as a function of $h t_{f} / d^{\prime 2}$ for M16 Grade 10.9 Hollo-bolts

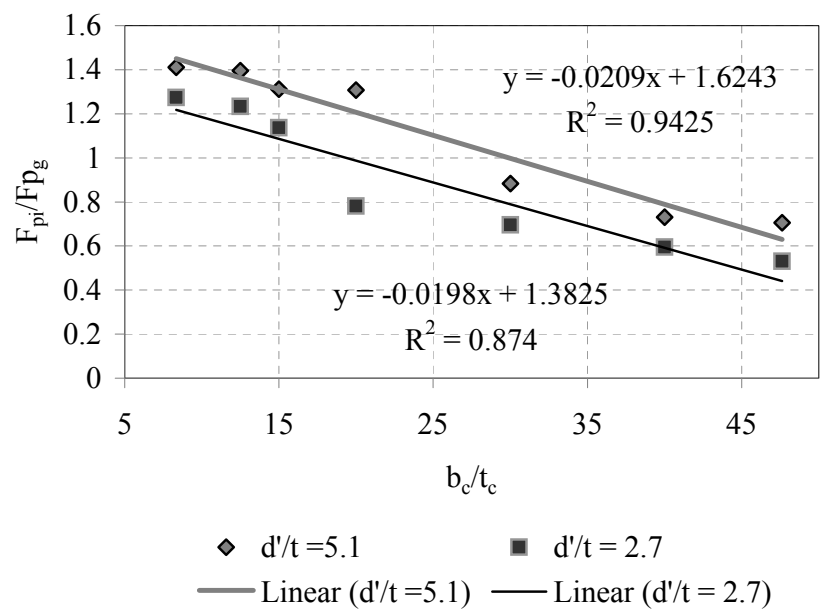

Figure 20: Relationship between $F_{p i} / F_{p g}$ (as defined by Equation 20) and $b_{c} / t_{c}$ for different $d^{\prime} / t_{f}$ ratios and M16 Grade 10.9 Hollo-bolts 


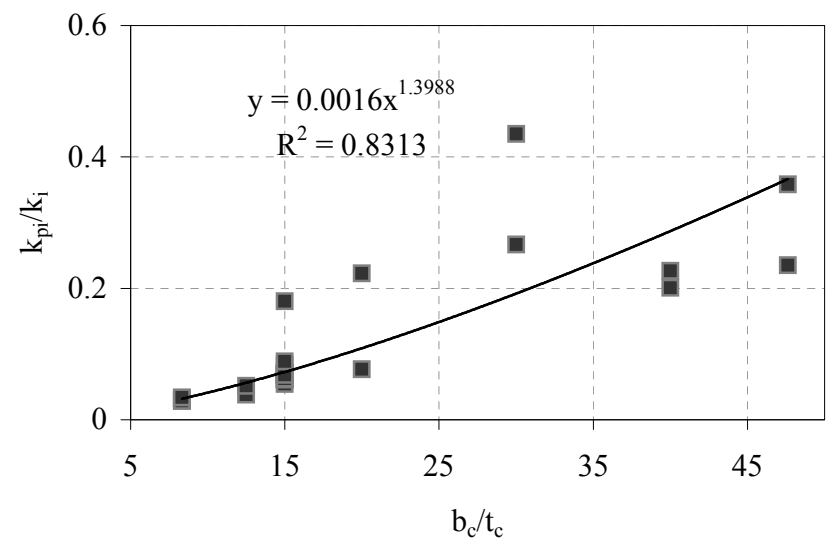

Figure 21: Relationship between strain hardening stiffness $\left(k_{p i}\right)$ and initial stiffness $\left(k_{i}\right)$ as a function of the column face slenderness $\left(b_{c} / t_{c}\right)$.

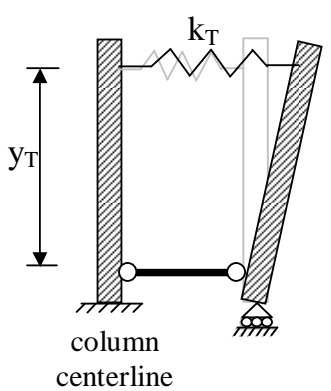

(a) Top and seat angle connections
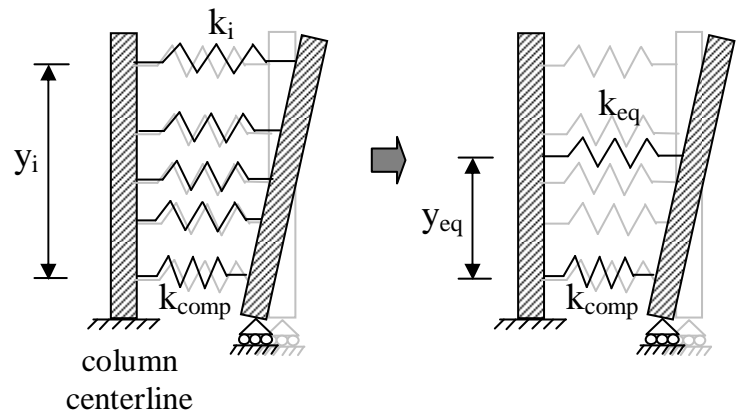

(b) Top, seat and web angle connections

Figure 22: Design-oriented simplified mechanical model of angle connection 


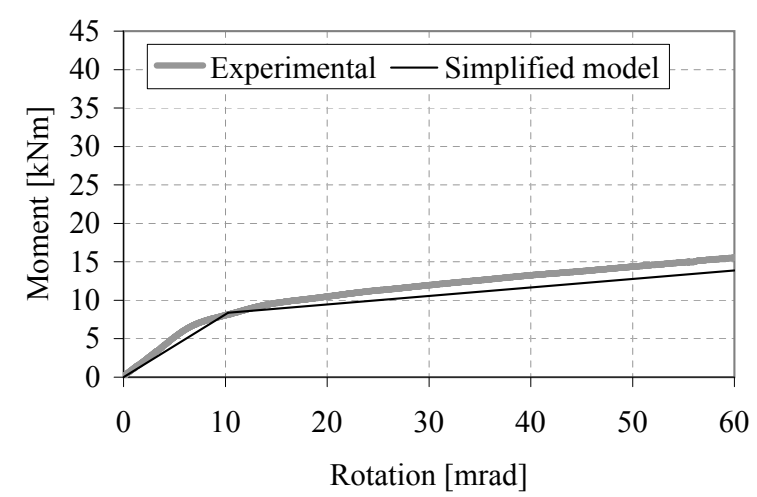

(a) Specimen A6.3-G8.8-d65-M

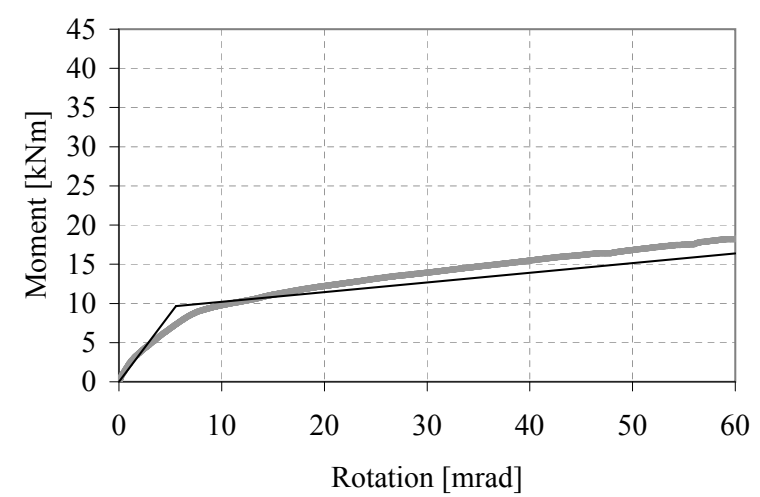

(c) Specimen A10-G8.8-d65-M

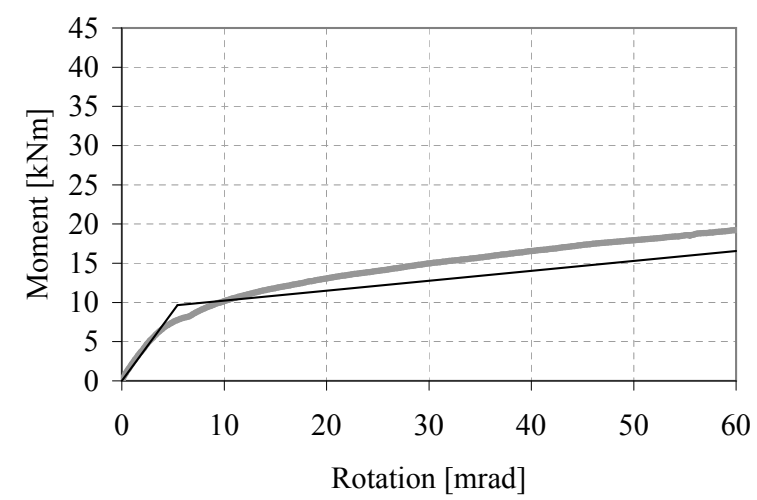

(e) Specimen A10-G10.9-d65-M

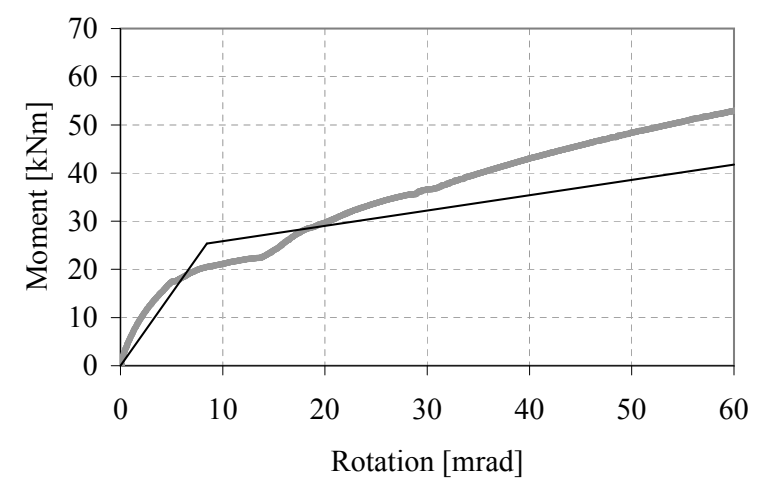

(g) Specimen C10-G10.9-d65-M

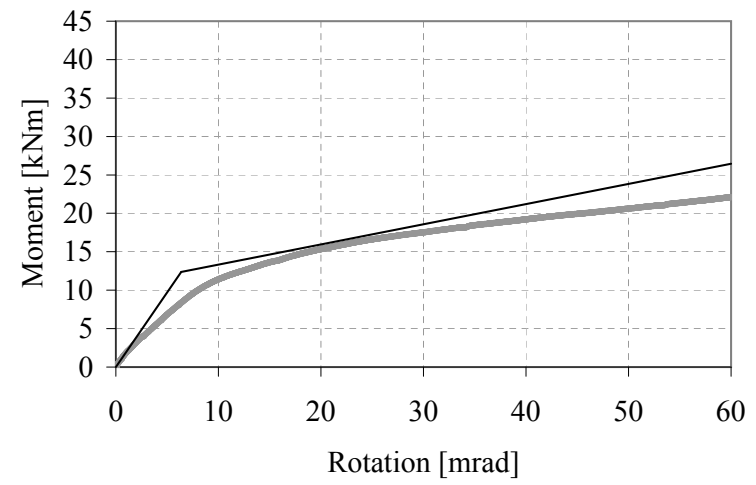

(b) Specimen A6.3-G8.8-d40-M

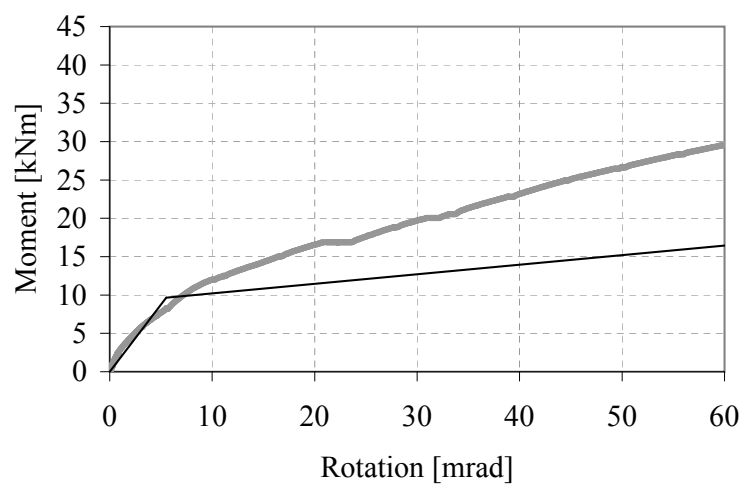

(d) Specimen A10-G8.8-d40-M

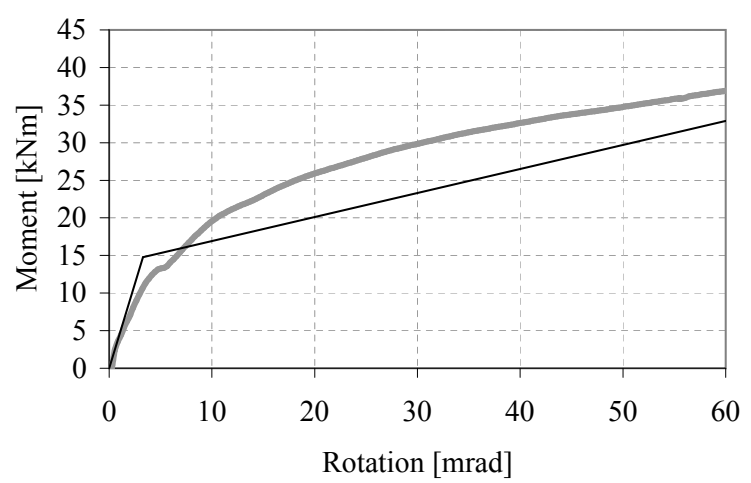

(f) Specimen A10-G10.9-d40-M

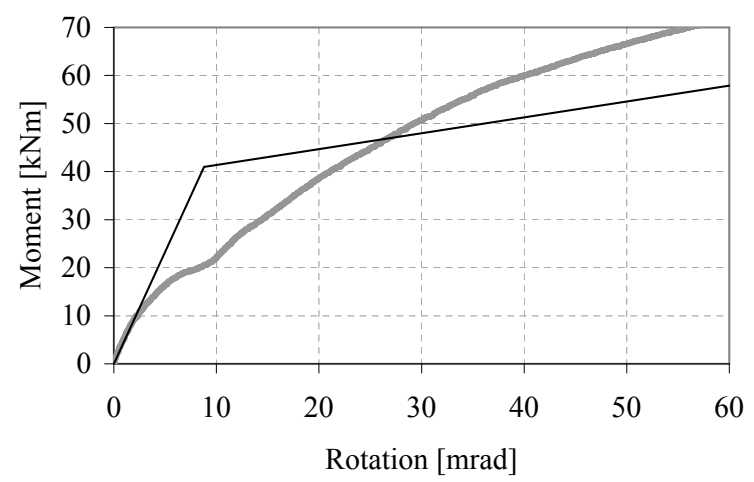

(h) Specimen C10-G10.9-d40-M

Figure 23: Comparison of experimental results and predictions of the more simplified design-oriented component model for monotonic tests. 


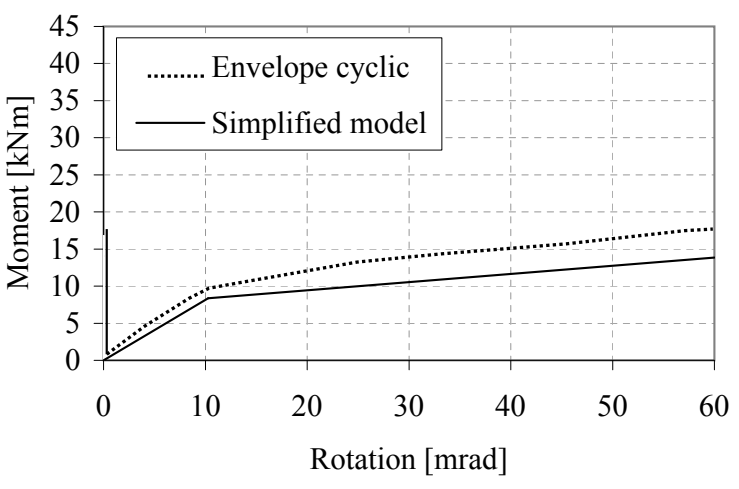

(a) Specimen A6.3-G8.8-d65-Y

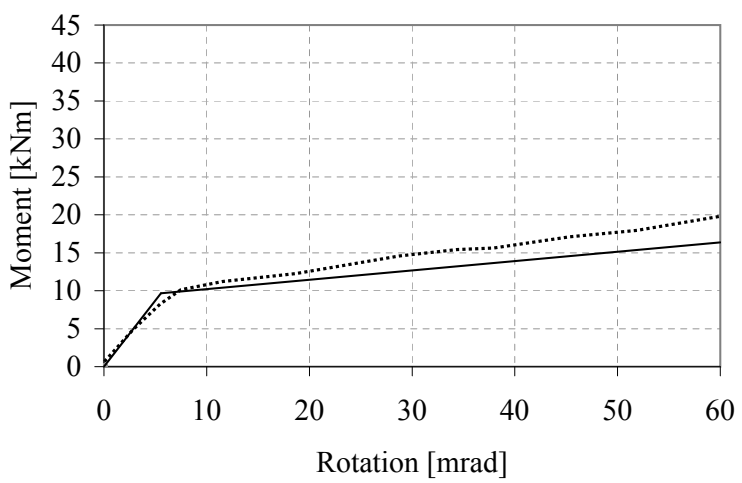

(c) Specimen A10-G8.8-d65-Y

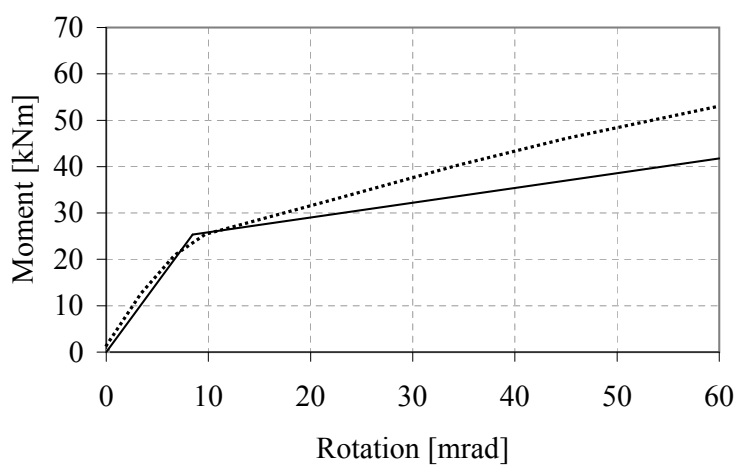

(e) Specimen C10-G10.9-d65-Y

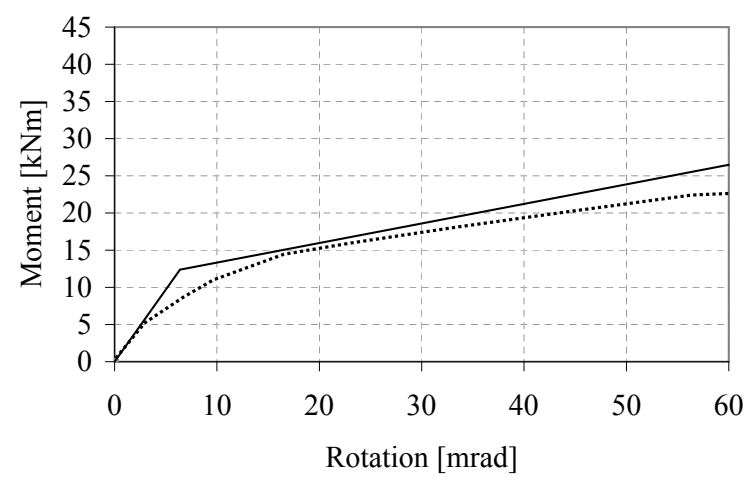

(b) Specimen A6.3-G8.8-d40-Y

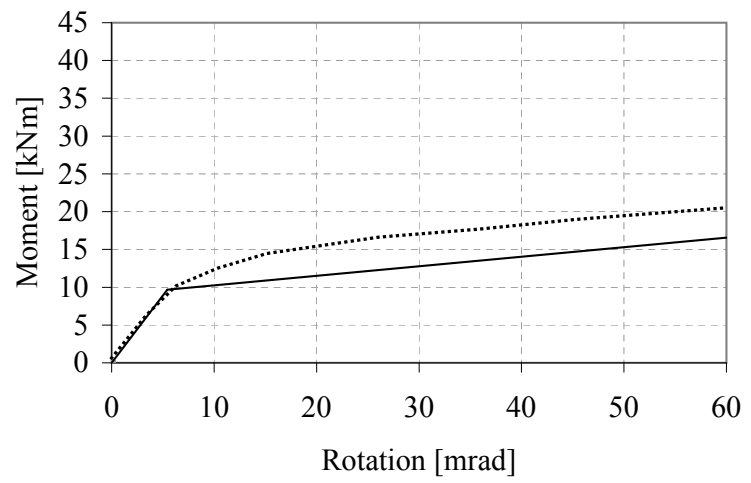

(d) Specimen A10-G10.9-d65-Y

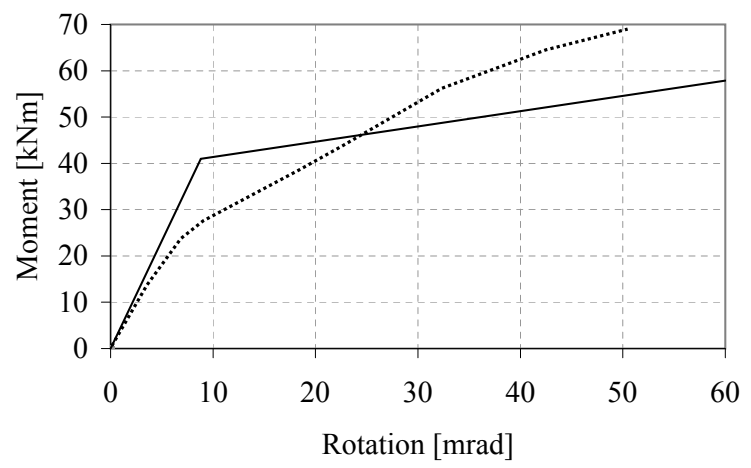

(f) Specimen C10-G10.9-d40-Y

Figure 24: Comparison of envelope of cyclic response and predictions of the more simplified design-oriented component model for cyclic tests. 